Chapman University

Chapman University Digital Commons

ESI Publications

Economic Science Institute

2015

\title{
The Effect Of Cognitive Load On Economic Decision Making: A Survey And New Experiments
}

Cary Deck

Chapman University, deck@chapman.edu

Salar Jahedi

RAND Corporation

Follow this and additional works at: http://digitalcommons.chapman.edu/esi_pubs

\section{Recommended Citation}

Deck, C. and Jahedi, S. (2015). “The Effect of Cognitive Load on Economic Decision Making: A Survey and New Experiments," European Economic Review 78, August 2015, pp. 97-119. DOI: 10.1016/j.euroecorev.2015.05.004

This Article is brought to you for free and open access by the Economic Science Institute at Chapman University Digital Commons. It has been accepted for inclusion in ESI Publications by an authorized administrator of Chapman University Digital Commons. For more information, please contactlaughtin@chapman.edu. 


\section{The Effect Of Cognitive Load On Economic Decision Making: A Survey And New Experiments}

\section{Comments}

NOTICE: this is the author's version of a work that was accepted for publication in European Economic Review. Changes resulting from the publishing process, such as peer review, editing, corrections, structural formatting, and other quality control mechanisms may not be reflected in this document. Changes may have been made to this work since it was submitted for publication. A definitive version was subsequently published in European Economic Review, volume 78, in 2015. DOI: 10.1016/j.euroecorev.2015.05.004

The Creative Commons license below applies only to this version of the article.

\section{Creative Commons License}

\section{(c) (1) (8)}

This work is licensed under a Creative Commons Attribution-Noncommercial-No Derivative Works 4.0 License.

\section{Copyright}

Elsevier 


\title{
The Effect of Cognitive Load on Economic Decision Making: A Survey and New Experiments
}

\author{
Cary Deck ${ }^{1,2}$ and Salar Jahedi ${ }^{3, *}$ \\ ${ }^{1}$ University of Arkansas \\ ${ }^{2}$ Chapman University \\ ${ }^{3}$ RAND Corporation
}

May, 2015

\begin{abstract}
Psychologists and economists have examined the effect of cognitive load in a variety of situations from risk taking to snack choice. We review previous experiments that have directly manipulated cognitive load and summarize their findings. We report the results of two new experiments where participants engage in a digit-memorization task while simultaneously performing a variety of economic tasks including: (1) choices involving risk, (2) choices involving intertemporal substitution, (3) choices with anchoring effects, (4) choices over healthy and unhealthy snacks, and (5) math problems. We find that higher cognitive load reduces numeracy as measured by performance in math problems. Moreover, within-subject analysis indicates that cognitive load leads to more risk-averse behavior, more impatience over money, and (nominally) more likelihood to anchor. We do not find any evidence that cognitive load increases impatience over consumption goods or unhealthy snack choices. Exploiting the panel nature of our data set, we find that those individuals who are most sensitive to cognitive load, as measured by a large drop in their own math performance across 1- and 8-digit memorization treatments, are driving much of the effect.
\end{abstract}

${ }^{*}$ The authors wish to thank Daniel Benjamin, Kristine Brown, Jeff Butler, Colin Camerer, Stefano DellaVigna, David Dickinson, Daniel Kahneman, Botond Köszegi, David Laibson, George Loewenstein, Sendhil Mullainathan, and Richard Thaler for their insightful comments. We are also grateful to Xirong Chen, Joshua Foster, and Valerie Spaink for their invaluable research assistance. Contact Info: Cary Deck, Department of Economics, Sam M. Walton College of Business, Business Building 402, Fayetteville, AR 72701-1201, USA, cdeck@walton.uark.edu; Salar Jahedi, RAND Corporation, 1776 Main Street, P.O. Box 2138, Santa Monica, CA 90407-2138, USA, sjahedi@rand.org 


\section{Introduction}

Identifying how individuals make decisions under uncertainty, how they make intertemporal trade-offs, and the extent to which their judgments are influenced by context are core components of understanding economic decisionmaking. Increasingly it has been demonstrated that individuals deviate systematically from classic assumptions; namely, they exhibit too much risk-aversion, they are overly impatient in the short-run, and they use non-informative cues in making decisions. Such deviations are often modeled by researchers as behavioral preferences (Köszegi and Rabin, 2006; Laibson, 1997; Tversky and Simonson, 1993), with the implicit notion that these preferences are stable within the individual. However, there is a large body of research suggesting that the expression of such preferences depend critically on the cognitive resources available to the decision maker. For example, people of high cognitive ability, as measured by their IQ score, are found to be more risk-tolerant, more patient, and less prone to anchoring effects than those with lower cognitive ability (Frederick, 2005; Burks et al., 2009; Dohmen et al., 2010; Benjamin et al., 2013; Bergman et al., 2010).

Cross-sectional studies typically encounter difficulties in pinning down the causal relationship between cognitive resources and decisions. Experimental research can shed light on this causal link by exogenously impairing cognitive resources in the lab. Researchers have employed several techniques to generate cognitive load; the most common method is to have subjects hold a 6-or-more-digit number in their memory while simultaneously making choices. The survey section of this paper reviews evidence of how performance across a variety of economic tasks is affected in experimental settings that directly manipulate cognitive load. Across studies, it appears that increasing cognitive load leads to poorer reasoning and math performance, more risk-aversion, and more impatient choices, although the evidence is mixed for each of these. Most experimental studies examining cognitive load focus on a single type of task and often have small samples and hypothetical stakes. A notable exception is the paper by Benjamin et al. (2013) which utilizes a series of hand-run experiments to test whether 7-digit number memorization affects performance on risk, patience, selfishness, and analytical tasks using a between-subjects design. While they are unable to definitively show that their number-memorization task was successful at impacting cognitive load (performance in the analytical task did not vary by treatment), their findings do indicate that subjects in the 7-digit treatment are more risk-averse than subjects with no memorization task.

Dual-system theories (Kahneman 2002; Kahneman 2011) offer a mechanism by which cognitive load can impact behavior. In this framework, people have an impulsive "intuitive" system and a cool "reasoning" system. When required to make a decision, the intuitive 
system quickly reaches a decision that the reasoning system can override for a cost. Insofar as risk-averse or impatient behavior is impulsive and undesirable and cognitive resources are abundant, the reasoning system can repress those preferences from being exhibited. Placing a person under cognitive load increases the workload of the reasoning system and hinders its ability to regulate choice, leading to less reasoned behavior. A number of models have operationalized these predictions (Fudenberg and Levine, 2006; Mukherjee, 2010).

Our paper reports the results of two experiments in which subjects are placed under cognitive load and asked a series of questions spanning multiple tasks. We improve on Benjamin et al. (2013) by using a larger sample size, exposing subjects to a different memorization problem for each question, and successfully manipulating cognitive ability, as measured by a drop in performance in a math task. The major contribution of our study, however, is that we employ a within-subjects design to test whether cognitive load has a systematic effect on individuals across multiple tasks. That is, we ask whether the same individuals whose arithmetic performance suffers most under cognitive load are the same individuals whose performances suffer in other tasks as well.

Our Experiment 1 reports on a computerized experiment that tests the causal effect that increased cognitive load has on (1) an incentivized arithmetic question, (2) an incentivized binary choice between a safe option and a risky gamble, (3) a hypothetical binary choice between two monetary sums paid at different times, and (4) an incentivized counting task with an uninformative anchor. In our first experiment, participants are given either a 1-digit or an 8-digit number to memorize and are incentivized to keep that number in their memory while completing a randomly determined task. The data show that an individual is more likely to make arithmetic mistakes, act risk-averse, and be susceptible to anchoring in the 8-digit treatment as compared to the 1-digit treatment. The results are driven mainly by those individuals who are most sensitive to cognitive load - defined as individuals whose math performance in the 8-digit treatment diminished the greatest when compared to their own math performance in the 1-digit treatment. Our findings for these incentivized tasks generally corroborate the existing literature, but the hypothetical intertemporal decision task does not. There we find that people become more patient when memorizing an 8-digit number. Furthermore, the result is mainly driven by those individuals least sensitive to cognitive load.

To explore why we find the puzzling results regarding patience, we conduct Experiment 2 using real stakes. Because this study involves intertemporal decisions, the subjects are required to sign up for two sessions exactly one week apart. ${ }^{1}$ We used the same general format

\footnotetext{
${ }^{1}$ One downside of using real stakes is that there is uncertainty from receiving future payoffs and this uncertainty can make impatience difficult to differentiate from risk-aversion. Experiment 1 uses hypothetical
} 
as Experiment 1, where participants are incentivized to memorize a number, then complete a task, and then recall the number. Four tasks were included in the second experiment: (1) a money impatience task, (2) a consumption impatience task, (3) an immediate snack choice task, and (4) a delayed snack choice task. In both of the impatience tasks, subjects had to make an incentivized binary choice between a small amount of money/snack today vs. a larger amount of money/snack in one week. In both of the snack choice tasks, subjects had to make an incentivized binary choice between a healthy or unhealthy snack that is awarded either immediately or in one week. The latter tasks are an attempt to replicate and extend Shiv and Fedorikhin's (1999) study, which found that cognitive load led to more unhealthy food choice. Selecting the unhealthy snack can be interpreted as being impatient since the subject is trading off immediate gratification against longer term health. Because Shiv and Fedorikhin had suggested physical proximity to the food is important, this study was handrun. In one treatment subjects were shown the actual food which would be received during the session. In the other, subjects were shown pictures of food which would be received in one week. ${ }^{2}$ The results of the second experiment reverse the results from the hypothetical task in Experiment 1: people under higher cognitive load acted more impatiently for real money. However we found no evidence that cognitive load affected choices in any of the food treatments. That is, we are unable to find that cognitive load affected impatience over consumption nor were we able to corroborate Shiv and Fedorikhin's finding that cognitive load is associated with more unhealthy snack choice.

The remainder of the paper is organized as follows: Section 2 provides a survey of the literature on cognitive load experiments. Section 3 discusses the methodology and results from Experiment 1. Section 4 discusses the methodology and results from Experiment 2. Section 5 makes concluding remarks.

\section{Cognitive Load Literature Survey}

The idea that individuals have limited cognitive resources is well established in psychology. Cognitive resources can be depleted in many ways. Imposing a burden on working memory has been shown to have adverse effects on performance in a variety of tasks that involve logic or reasoning. Miller (1956) argues that people are able to hold only about seven $( \pm$

stakes to equalize uncertainty regarding payments. In Experiment 2 we attempt to minimize the uncertainty of future payoffs by requiring that everybody return in one week to collect the bulk of their show-up fee.

${ }^{2}$ The first experiment consisted of 1-digit and 8-digit treatment groups. The second experiment consisted of three within subject treatments: no memorization, 2-digit memorization and 8-digit memorization. These changes were due to a desire to be compatible with previous studies on food choice and to allow for the possibility that any number memorization constituted some cognitive load. 
2) items in their short-term memory at once, after which performance can greatly suffer. Some studies suggest that having too many options can have the same effect. Indeed, menus containing too many options are often associated with poor choices, even when stakes are large such as choosing retirement savings and health insurance plans (Iyengar et al., 2004; Schram and Sonnemans, 2011; Abaluck and Gruber, 2011). A set of recent papers (Besedeš et al., 2012; Besedeš et al., 2014) find experimental evidence that subjects are less likely to select objectively optimal options from larger choice sets than from smaller ones, and that the way that options are presented can alleviate this effect.

Our emphasis is on studies that directly manipulate cognitive load to ascertain how doing so affects economic decisions, specifically pertaining to arithmetic performance, risk, intertemporal choice, healthiness in snack choice, generosity, and strategic behavior, among others. Table 1 summarizes a number of these studies. While there are many different methods for inducing cognitive load, most require the participant to hold information in memory. Harkening Miller (1956), most studies choose to directly manipulate cognitive load by asking subjects to memorize numbers with 7 or more digits.

De Neys (2006) finds that the ability to spot flawed logical arguments in syllogisms is lower for individuals given complex dot patterns to memorize than for people given simple patterns. Sprenger et al. (2011) find a greater rate of violations in probability judgments when individuals are memorizing longer rather than shorter strings of letters. Rydval (2011) finds that performance on a time-series forecasting task is lower when individuals are given the pertinent data sequentially, forcing individuals to retain some information in memory while doing the task, rather than simultaneously. Benjamin et al. (2013) looked for, but did not find, evidence that cognitive load statistically reduces performance on SAT-type math problems (arithmetic, algebra, geometry, and probability). Mani et al. (2013) experimentally prime rich and poor people to think about a looming car repair that varies in its cost. They find that priming reduces cognitive performance on IQ tests among poor participants, but not among well-off participants. The authors conclude that the context of poverty imposes load and impedes cognitive capacity. 


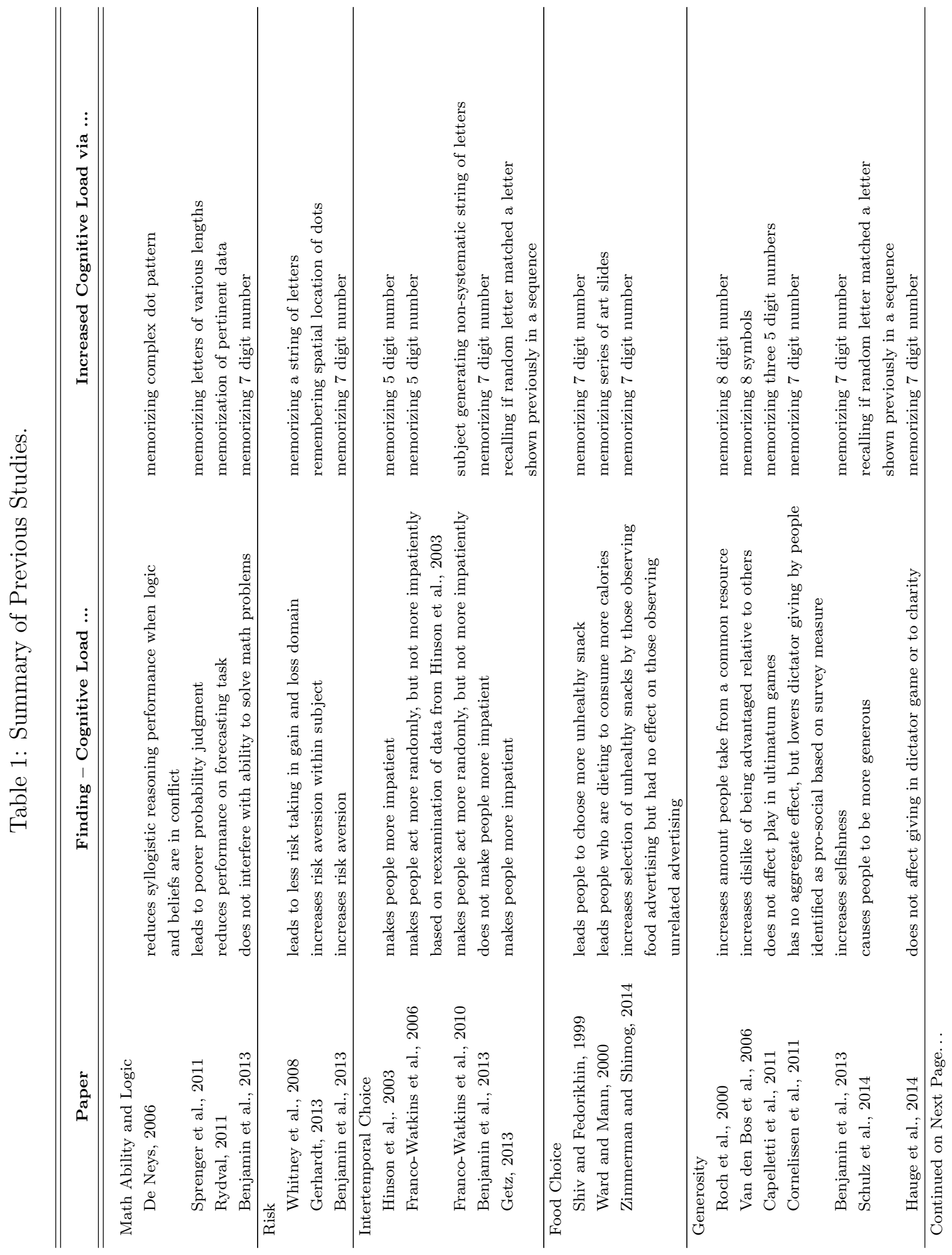




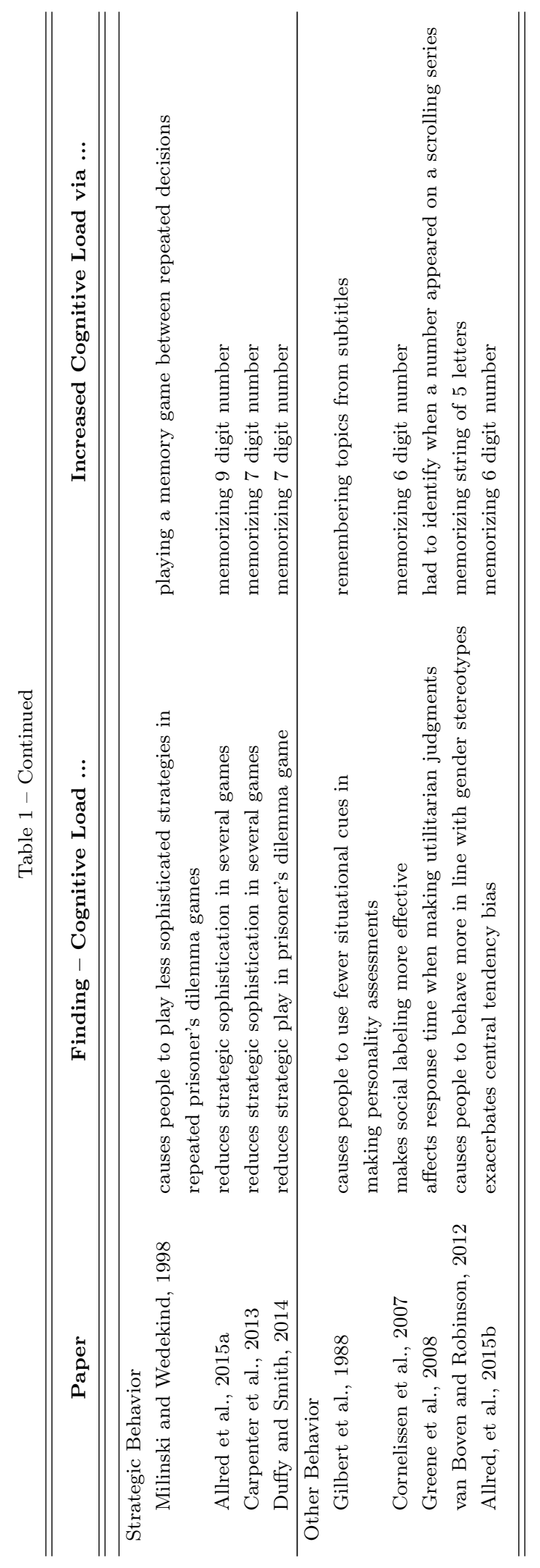


A number of papers have examined how cognitive load affects decisions involving risk. In general, most studies indicate that people under cognitive load take fewer risks relative to those under no cognitive load (Whitney et al., 2008; Gerhardt, 2013; and Benjamin et al., 2013). This finding seems consistent with papers that have examined how cognitive ability affects risk-taking. Individuals with lower cognitive ability, as measured by IQ tests, are found to be more risk-averse (Oechssler et al., 2009; Burks et al., 2009; Dohmen et al., 2010; Beauchamp et al., 2012; Benjamin et al., 2013). Of course, other methods have also been used to manipulate reasoning and the results do not always replicate. For instance, alcohol and sleep deprivation are thought to lower cognitive ability, but Corazzini et al. (2014) find no effect of alcohol consumption on risk taking in the lab, while McKenna et al. (2007) find that sleep deprivation leads to more risk neutral behavior. Similarly, Butler et al. (2013) find that risk tolerance increases when individuals are primed to rely on intuition rather than reasoning.

The evidence on how cognitive load affects impatience is somewhat mixed. An influential paper by Shiv and Fedorikhin (1999) finds that individuals memorizing a 7-digit number were $22 \%$ more likely than individuals memorizing a 2-digit number to choose chocolate cake over fruit salad. The authors proposed that the cognitive load task increased reliance on intuitive choice and thus led to more impulsive behavior. Other papers similarly find that cognitive load is associated with poorer dietary choice (Ward and Mann, 2000; Zimmerman and Shimog, 2014), the logic being that one is trading off immediate gratification against long-term costs. Hinson et al. (2003) and Getz (2013) study impatience over monetary outcomes using standard intertemporal questions to find that people exhibit more impatient behavior when subjected to cognitive load. However, Franco-Watkins et al. (2006) re-examine the data from Hinson et al. (2003) and conclude that people are not necessarily more impatient when under cognitive load, but rather subjects simply make more random decisions, as might be expected given their degraded logic skills. In fact, Franco-Watkins et al. (2010) provide direct experimental support for cognitive load leading to more random behavior rather than impatient behavior. This runs somewhat in contrast with the literature on cognitive ability. Shamosh and Gray (2008) conduct a literature review and a meta-analysis and conclude that higher cognitive ability is associated with less impatience. Oechssler et al. (2009) also find a similar pattern; low Cognitive Reflective Task (CRT) scores are associated with greater impatience. Corazzinni et al. (2014) find that alcohol consumption makes people less patient.

We are not aware of studies that vary cognitive load when examining anchoring effects, but at least two studies look at the relationship between cognitive ability and anchoring. Oechssler et al. (2009) find no relationship between CRT score and anchoring and Bergman et al. (2010) find that people with greater cognitive skills are less susceptible to anchoring. 
The effect of cognitive load on other behaviors, such as generosity, is unclear. Hauge et al. (2014) and Cappelletti et al. (2011) find that being under cognitive load does not affect generosity in the dictator and ultimatum games, respectively. Benjamin et al. (2013) and to some degree Cornelissen et al. (2011), find that subjects under cognitive load are more selfish in dictator games, while Roch et al. (2000) find people under cognitive load are more selfish in common resource games. On the other hand, Van den Bos et al. (2006) and Schulz et al. (2014) find the opposite effect: generosity increases when subjects are under cognitive load. This is in line with Rand et al. (2012) who find that across ten experimental designs, subjects who reach their decisions more quickly are more cooperative. As it relates to cognitive ability, Chen et al. (2013) find that better scores on SAT math questions are associated with more generosity whereas higher GPAs are associated with more selfishness. The alcohol study of Corazzinni et al. (2014) finds that drinking makes people less generous.

The application of cognitive load to strategic games is interesting, though complicated. In such cases, players must not only compute the optimal strategy, but must also form beliefs about the behavior of their opponent, and beliefs about their opponent's beliefs (see Deck and Jahedi, 2015a for a related discussion on impatience). In games of dominance like the Prisoner's Dilemma (PD), or games that can be solved iteratively (Milinski and Wedekind, 1998; Carpenter et al., 2013), cognitive load is associated with decreased cooperation rates in the PD game and lower performance in iteratively solvable games. In complex games such as a repeated PD setting, Duffy and Smith (2014) find that cognitive load lowers strategic sophistication as measured by endgame play. Allred et al. (2015a) argue that cognitive load acts in strategic games by simultaneously decreasing computational accuracy and the accuracy of beliefs in others' actions.

Cognitive load and cognitive ability have been examined in several other settings as well. In social settings that require cognitive resources, Gilbert et al. (1988) find that the ability of individuals to use situational cues suffers. Greene et al. (2008) find that for utilitarian judgments, such as the acceptability of killing a baby to save the lives of others, response times, but not necessarily choices, are impacted by cognitive load. Block et al. (2010) conduct a meta-study that looks at how cognitive load affects individual's estimation of time duration. The authors find that accuracy in estimation times depends on whether or not the person knows if she will have to make a judgment before completing the task. Allred et al. (2015a) find that people under higher load tend to evaluate the length of a line as closer to mean of a comparison group, exacerbating central tendency bias.

In sum, the aggregate choices of respondents under cognitive load tend to be no better, and often worse, than the aggregate choices of individuals who are not under cognitive load across a wide range of economically relevant activities. Overall, the research suggests 
that observed behavior can be swayed by access to cognitive resources, and that it is not appropriate to think about individuals acting upon one single risk attitude or one level of impatience.

\section{Experiment 1}

\subsection{Methodology}

A total of 112 participants were recruited for the 90 minute study. The experiment was conducted across six sessions at the Behavioral Business Research Lab (BBRL) at the University of Arkansas. The show-up payment was $\$ 10$ and participants were paid an additional $\$ 13.31$ on average. Prior to the start of the experiment, all participants in each session were seated at a computer and asked to read the experimental instructions. ${ }^{3}$ The instructions were interactive and included practice questions for each type of task that would appear in the experiment, along with a quiz asking participants to correctly identify the payoff associated with making various choices.

The four main types of tasks in this experiment were (1) arithmetic, (2) risk, (3) impatience, and (4) anchoring. For each task, many different sub-tasks could be encountered. Table 2 describes the sub-tasks and methods that were used to create specific realizations. Sample screen shots displaying questions for each task are shown in Figure 1.

Once a participant had finished reading the instructions, the 80 period experiment began. In each period, a number appeared for three seconds on the participant's computer screen. Participants were asked to keep this number in their memory. Next, the subject was given a randomly determined task to complete. The task was generated at random with replacement, meaning that different subjects would complete different versions of each task resulting in a different total number of observations for each task type. Once the task was completed, participants were asked to recall their number. If they recalled the number correctly, their memorization payoff for the period was $\$ 22$. Otherwise it was $\$ 0$. The payoff associated with memorization was intentionally higher than the average payoff for the main task so that participants with limited memory would devote their main attention to memorization rather than the other task. This increased the likelihood that our cognitive load manipulation would have the desired effect. Some subjects were shown 8-digit numbers to memorize in periods 1 - 40 and then shown 1-digit numbers to memorize in periods 41 - 80. Other

\footnotetext{
${ }^{3}$ The experiment was programmed and conducted in z-Tree (Fischbacher, 2007). The instructions, which include screen shots of the pages that were shown, can be found online at https://sites.google.com/site/salarj/research
} 


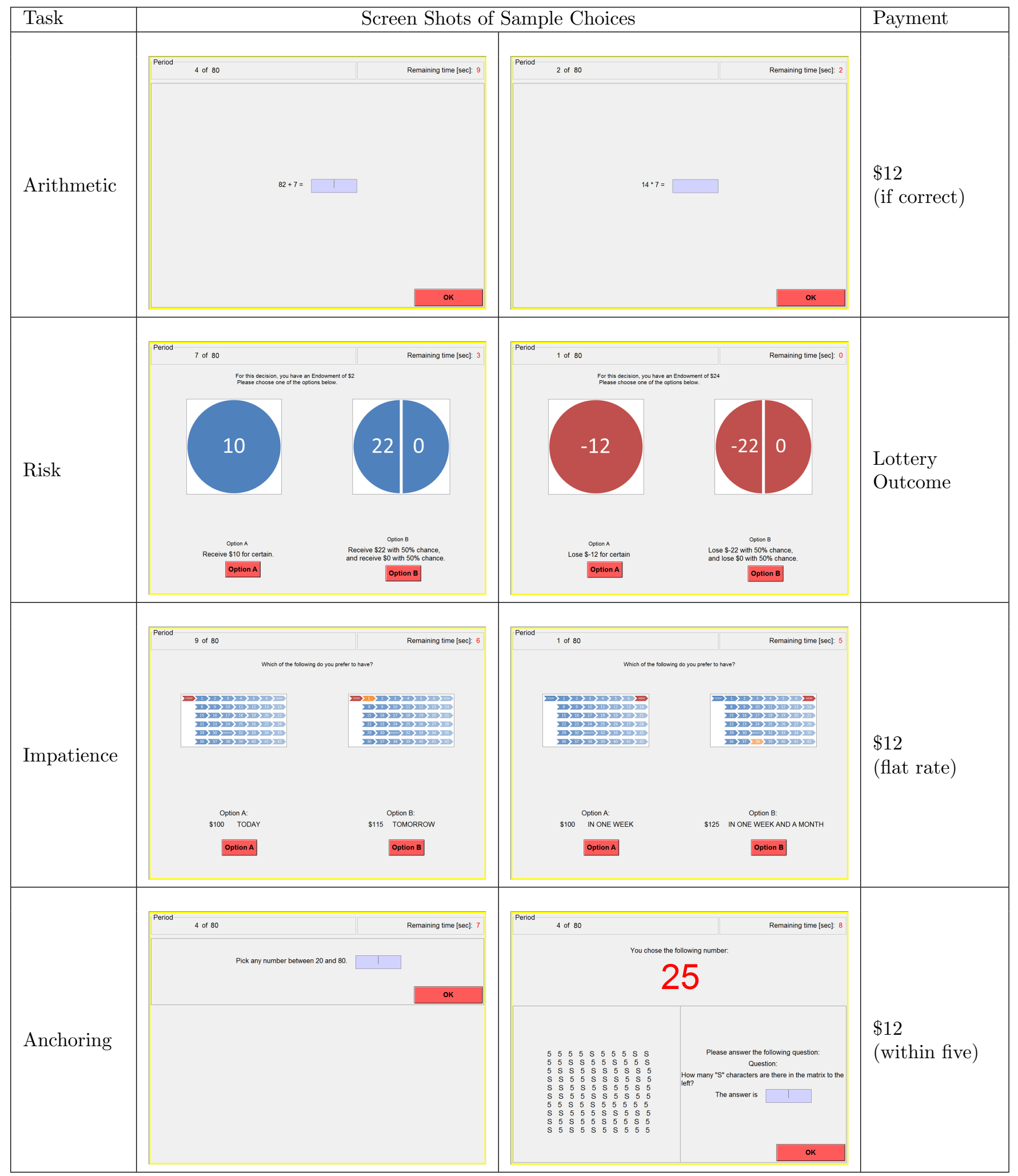

Figure 1: Sample Screen Shots for Different Tasks 
Table 2: Tasks in Experiment 1.

\begin{tabular}{|c|c|}
\hline $\begin{array}{l}\text { MAIN TASK } \\
\text { sub-task }\end{array}$ & Description of how random tasks are generated \\
\hline ARITHMETIC & paid $\$ 12$ for correct answer. \\
\hline $\begin{array}{l}\text { Addition } \\
\text { Multiplication }\end{array}$ & $\begin{array}{l}\text { Add } a_{1}+a_{2} \text { where integer } a_{1} \sim U\{11, \ldots, 99\} \text { and integer } a_{2} \sim U\{1, \ldots, 9\} \\
\text { Multiply } m_{1} \times m_{2} \text { where integer } m_{1} \sim U\{13, \ldots, 19\} \text { and integer } m_{2} \sim U\{5, \ldots, 9\}\end{array}$ \\
\hline RISK & paid based on outcome \\
\hline in Gain Domain & $\begin{array}{l}\text { Integer } g \text { drawn from } \sim U\{8, \ldots, 15\} \text {. Given additional endowment of } 2 \text {. } \\
\text { Binary choice of guaranteed } g \text { or } 50 / 50 \text { chance of receiving }(2 g+2,0)\end{array}$ \\
\hline in Loss Domain & $\begin{array}{l}\text { Integer } g \text { drawn from } \sim U\{8, \ldots, 15\} \text {. Given additional endowment of } 2 g+4 \text {. } \\
\text { Binary choice of guaranteed }-g-2 \text { or } 50 / 50 \text { chance of receiving }(0,-2 g-2)\end{array}$ \\
\hline \multirow[t]{2}{*}{ IMPATIENCE } & paid $\$ 12$ so choice is hypothetical \\
\hline & $\begin{array}{l}\text { Binary choice between } \$ 100 \text { at time } T \text { or } \$ F \text { at time } T+t \\
\text { where } F \text { equally likely to be }\{105,110,115,125\} \\
\text { where } T \text { is equally likely to be }\{\text { Today, In One Week, In One Month\}. } \\
\text { and } t \text { is equally likely to be }\{\text { Day, Week, Month }\} \text {, except when } \\
T=\text { "In One Month," when, } t \text { is equally likely to be }\left\{\text { Day, Week } .^{*}\right.\end{array}$ \\
\hline \multirow[t]{2}{*}{ ANCHORING } & paid for $\$ 12$ if within five of the accurate count \\
\hline & $\begin{array}{l}\text { Subject first picks an integer between } 20 \text { and } 80 \text { and then must count S's } \\
\text { in a } 10 \text { by } 10 \text { table consisting of } 5 \text { 's and S's. The \# of S's is equally likely to be: } \\
\text { (integer } \sim U\{0, \ldots, 30\} \text { ), (integer } \sim U\{31, \ldots, 70\} \text { ), (integer } \sim U\{71, \ldots, 100\} \text { ). }\end{array}$ \\
\hline
\end{tabular}

${ }^{*}$ When designing this experiment, we provided subjects with a visual so that it would make it easier to envision the dates between payoffs (see Figure 1). The image that accompanied the tasks was a six-week calendar and thus could not support a decision spanning two months.

subjects first memorized 1-digit numbers and then memorized 8-digit numbers. The order was randomly determined for each subject.

Participants were paid for exactly one of their responses, a fact that was explained to them in advance. At the end of the experiment, the computer randomly chose one of the 80 periods to use in determining the subject's payoff. For the randomly selected period, the computer then randomly determined if the subject would be compensated for the memorization or the main task. Randomly selecting one task for payment was intended to eliminate wealth effects. If subjects do not view each task in isolation, then it is possible that subjects regard the payments for the decision task and the memory task as substitutes. However, we do not believe that such wealth effects, if they exist, are very large.

There are two main ways that wealth effects can differ across 1- and 8-digit treatments. First, subjects may frame the memory task and decision task in a given period as isolated from the tasks in other periods. This would imply that decisions in the 1-digit treatment would be associated with higher expected wealth than decisions in the 8-digit treatment 
and might reduce the overall effort level exerted by subjects. However, performance in the math task is $12 \%$ better in the 1-digit treatment, indicating that subjects are not shirking in those tasks where their expected wealth is higher. Second, subjects may have inaccurate beliefs regarding their future memory performance. If so, their expected wealth would change over the course of the experiment as they learn about their own memory performance. In such cases, we would expect to see differences in performance between those who started the experiment with the 8-digit treatment and those who started the experiment with the 1-digit treatment. However, we do not observe significant differences in behavior due to ordering.

Before presenting the results we provide a brief explanation for the specific tasks that we selected. Our primary interest is in how cognitive load impacts individual decision making and thus our tasks are limited to those activities measuring core preferences and ability rather than strategic or social concerns. In part this is due to the fact that strategic and social concerns may depend not only on the cognitive load of the decision maker, but also on the decision maker's beliefs about how cognitive load impacts others as well. The Arithmetic task is used as a control to identify whether the number memorization activity actually does manipulate cognitive load. Both addition and multiplication problems are included to gauge the severity of the manipulation on decision making. If memorizing a large number does not affect ability to do multiplication then a more extreme cognitive load manipulation would be warranted. At the same time, if people cannot do simple addition when memorizing a number then the manipulation might be too strong for choices to be meaningful.

Our Risk task was designed to be a simple choice between a safe and risky option: subjects had to choose between a low-paying safe option that always appeared on the left-hand side of the screen and a higher-paying risky option that always appeared on the right-hand side of the screen (Gerhardt, 2013; Benjamin et al., 2013, discuss comparisons of choices over safe and risky options verses two risky options). The higher-paying risky option had an expected value that was always $\$ 1$ higher than that of the safe option. ${ }^{4}$ Furthermore, the Risk task covered both the gain and loss domain. In the gain domain, gambles always returned positive outcomes whereas in the loss domain, gambles always returned negative outcomes. Since participants were not asked to pay money out of pocket, we follow the standard procedure that risks framed as losses were accompanied by a large-enough endowment to cover any losses. In fact, the endowments in both domains were assigned such that the choice between safe and risky choices gave rise to the identical payoffs. In that sense, the difference between the conditions is a mere framing effect. If subjects realize this or do not internalize the initial

\footnotetext{
${ }^{4}$ In our risk tasks, the sure option returned an average payment of $\$ 9.50$ whereas the lottery option returned an average 50/50 gamble of gaining $\$ 21$ or gaining $\$ 0(\mathrm{EV}=\$ 10.50)$. Under the standard model where people have constant relative risk aversion and have a lifetime wealth of $\$ 100,000$, a person will only choose the sure option over the gamble if their risk aversion coefficient is greater than 1825 !
} 
endowment, then they may perceive both types of risk tasks to be in the gain domain.

Our Impatience task was done for hypothetical stakes and always offered an option between $\$ 100$ at an early date that appeared on the left-hand side of the screen, and an option for a larger amount at a future date that always appeared on the right-hand side of the screen. This task was intentionally made to be hypothetical so to get at time preferences without being concerned about the uncertainty related to future payments (see Deck and Jahedi, 2015b for a discussion). While this design removes the uncertainty associated with measuring time preferences, it potentially reduces the weight of each decision given that choices are hypothetical. $^{5}$

Finally, our Anchoring task is based on the Wheel-of-Fortune task introduced in Tversky and Kahneman (1974), where a randomly generated number was found to influence subjects' answers to an independent question. We created an abstract version of the task to allow for scalability in a repeated setting. ${ }^{6}$

\subsection{Results}

We examine how a cognitive load manipulation affects the choices made in Arithmetic, Risk, Impatience, and Anchoring tasks. In Table 3, we report the summary statistics by treatment, and the data are presented graphically in Figure A.1 of the Appendix. For the Arithmetic task, performance in the addition and multiplication problems are reported separately. For the Risk task, risks framed in gains and losses are reported separately. For the Impatience task, options involving an immediate payoff and only future payoffs are reported separately. A total of 22 observations are dropped in the risky choice tasks (10 in the gain frame, 12 in the loss frame) and a total of 235 observations are dropped in the Anchoring task since no decision was made prior to time running out.

A comparison of the raw means in the table indicate that digit recall was significantly higher for those in the 1-digit group than for those in the 8-digit group (difference $=53.1 \%$, $p$-value $<0.001$ using a two-sample unpaired t-test). This result signals that 8-digit memorization is difficult. To test whether our cognitive load manipulation had its intended effect, we can compare individuals' performance in the Arithmetic task, which is objectively measurable. For the Arithmetic task, addition performance was not affected by cognitive load (difference $=0.82 \%, p$-value $=0.531$ using a two-sample unpaired t-test), whereas perfor-

\footnotetext{
${ }^{5}$ One adverse result of this design is that individuals may learn to choose the option on the right-hand side of the page to save time since the 'Continue' button is located in the same general area of the screen.

${ }^{6}$ Because it is easy to determine the number of S's in a table of 100 characters if there are very few or very many, we intended to make such realizations rare by increasing the likelihood that the number of S's was moderate, but we inadvertently used a distribution to determine the number of S's that was nearly uniform (see Table 2). Subjects were not informed of this generation process.
} 
Table 3: Summary Statistics for Experiment 1.

\begin{tabular}{lcc}
\hline & 1-DIGIT & 8-DIGIT \\
& Percentage \\
& \# of Responses \\
\hline Digit Memorization & $96.3 \%$ & $43.3 \%$ \\
& 4480 & 4480 \\
\hline Correct Addition & $97.8 \%$ & $96.9 \%$ \\
& 312 & 294 \\
\hline Correct Multiplication & $71.6 \%$ & $55.9 \%$ \\
& 634 & 639 \\
\hline Risky Choice (gains) & $59.5 \%$ & $52.7 \%$ \\
\hline Risky Choice (loss) & 662 & 662 \\
\hline Early Option & $45.7 \%$ & $43.9 \%$ \\
(today vs. future) & 588 & 640 \\
\hline Early Option & $35.8 \%$ & $31.6 \%$ \\
(future vs. future) & 452 & 459 \\
\hline S-Count within & $30.2 \%$ & $25.9 \%$ \\
Anchoring Range & 871 & 815 \\
\hline
\end{tabular}


mance in multiplication did differ (difference $=15.7 \%, p$-value $<0.001$ using a two-sample unpaired t-test). ${ }^{7}$

We conduct the remaining analysis in two parts. First, we analyze the effect of cognitive load on each task separately. To simplify the analysis, the data for all questions in each main task are pooled. That is to say, for the Arithmetic task, addition and multiplication problems are reported together; for the Risk task, gambles in gains and gambles in losses are combined; and for the Impatience task, short-run and long-run tradeoffs are similarly pooled. We discuss the rationale for pooling below, and include the non-pooled regression results in Table A.1 of the Appendix. Second, we take advantage of the panel structure of our data to identify those individuals who are most sensitive to cognitive load as measured by the change in their arithmetic performance across the 1-digit and 8-digit treatments. We then test whether those identified as most sensitive to cognitive load have a relatively larger change in performance across all of the tasks.

For the Risk task, cognitive load lowers risk-taking overall, regardless of whether the risk is framed as a gain or a loss; though, the initial risk-taking level as well as the magnitude of the effect differs across gains and losses. Prospect theory predicts that people are more risk-averse in gains and more risk-loving in losses; however, we find no evidence supporting this proposition in our data. Indeed, risk aversion is slightly higher in the loss frame. Our inability to find risk-loving behavior in losses is consistent with Whitney et al. (2008) and Benjamin et al. (2013) who similarly find that risk-taking does not differ across gain and loss frames. For the Impatience task, cognitive load increased the likelihood of choosing the future option, regardless of whether the early option was available immediately or in the future. The Impatience task also has theoretically different predictions depending on sub-task. Laibson (1997) and others argue that people are more impatient when making a tradeoff between today and a future period than when making a tradeoff between two future periods. However, we find no evidence for such $\beta-\delta$ preferences: difference in behavior between those making decisions regarding today and a future period are the same as those making a decision between two similarly spaced future periods. ${ }^{8}$ Our inability to find patient

\footnotetext{
${ }^{7}$ Table A.1 shows that the difference is significant, even after clustering the standard errors by subject.

${ }^{8}$ Table 3 gives the appearance that there is evidence for hyperbolic discounting. A closer look at the data, however suggests otherwise. There is obviously evidence for delta-discounting: as the payment for the delayed option is pushed even further into the future, people choose the earlier option. However, there is not much evidence for beta-discounting: when the early option is today, people do not seem to be any more impatient than when the early option is in the future. The reason that the table shows people are more likely to choose the Early Option when making a choice between today and a future period is because there are proportionally more observations with a one-month delay as compared to the future periods (see Table 2 for a description of the design). Once we control for the date of the delayed option in a regression, there is no difference between the impatience exhibited for decisions having a today choice and impatience exhibited for decisions having only future choices.
} 
behavior for future tradeoffs is consistent with the cognitive load findings of Benjamin et al. (2013). In the Risk and Impatience tasks, the null hypothesis that the parameter on the treatment effects in Table A.1 is the same across sub-tasks cannot be rejected based on a generalized Hausman specification test (for the Risk task, $p=0.2957$; for the Impatience task, $p=0.9870)$. In the Arithmetic task, the treatment effect does differ based on addition or multiplication task (for the Math task, $p<0.0001$ ). However, we choose to pool this data as well, for the sake of consistency; though our identification is mainly based off of the multiplication treatment.

An OLS regression is run on each task separately (Arithmetic, Risk, Impatience, and Anchoring) on a dummy variable for the 8-digit treatment. ${ }^{9}$ All regressions include subjectfixed effects and cluster standard errors by participant, although the results do not depend on that. ${ }^{10}$ The treatment effect of cognitive load on each of the four main tasks can be found in Model 1a, Model 2a, Model 3a, and Model 4a respectively of Table 4. The results from Wald tests indicate that in the 8-digit treatment as compared to the 1-digit treatment, participants perform $12.2 \%$ worse at arithmetic problems $(p<0.001)$, are $5.4 \%$ more likely to choose the safe option in the Risk task $(p=0.025)$, and are $4.1 \%$ more likely to choose the later-option in the Impatience task $(p=0.025)$. For the Anchoring task, we employ a difference-in-difference procedure to identify the effect of anchoring on guesses of individuals in the 1-digit and 8digit treatments, after controlling for the true number of S's. A Wald test indicates that the random number between 20 and 80 input in the first stage significantly influences the guesses of the 1-digit treatment in the Anchoring task $(p=0.066)$. For every digit increase in this number, guesses of subjects in the 1-digit treatment increased by 0.068 units. In contrast, guesses of subjects in the 8-digit treatment increased by 0.104 units $(=0.068+0.034)$ for every unit increase in the anchor (a Wald test rejects the hypothesis that the sum of the slope coefficients equals zero, $p$-value $=0.042$ ). However, as the coefficient on Anchor $\times$ 8-digit is not significant, this means that we do not find that individuals memorizing an 8-digit number are significantly more likely to anchor. A more detailed breakdown of choices by sub-task can be found in Figure A.2 of the Appendix.

In the second part of our analysis, we take advantage of the panel structure of our data set to test whether those individuals that are most sensitive to cognitive load, as measured

\footnotetext{
${ }^{9}$ We report the results using a linear probability model because it has a transparent interpretation. Results from a probit analysis can be found in Table A.2 of the Appendix. It can readily be seen that the findings do not differ across the regression specifications.

${ }^{10}$ If we were to run statistical tests without clustering using a $t$-test or a Mann-Whitney test, the results would be much more significant. We have opted to cluster the standard errors at the subject level, but it is possible to cluster it at a broader level, such as at the session level, or at a finer level, such as at the task level. We have compared the results at different clustering possibilities and it makes little difference. Ideally, the cluster should be set at the broadest reasonable level, which we thought to be at the subject level.
} 


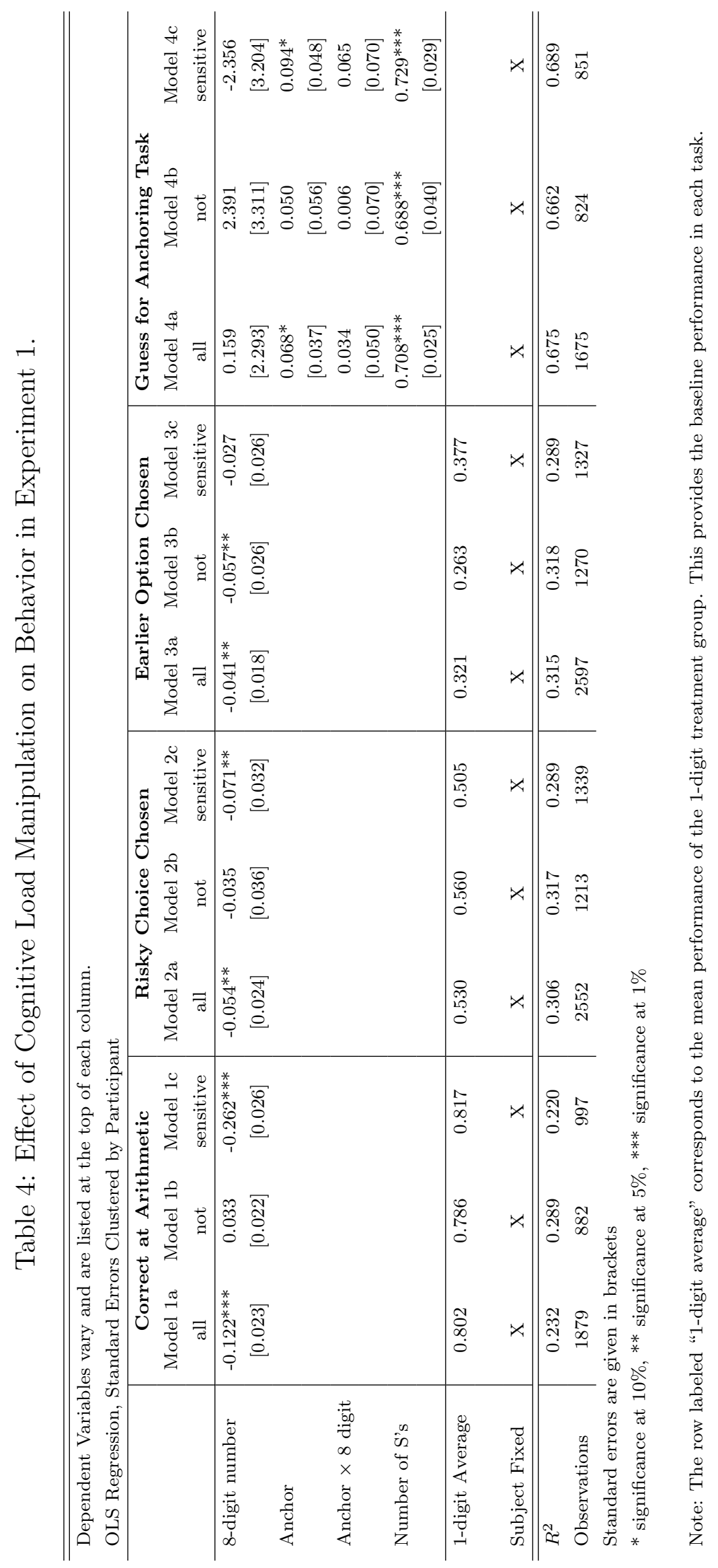


by the change in arithmetic performance between the 1-digit and 8-digit treatments, are also more likely to change their behavior in the other three tasks. For each person, we first calculate the difference between the fraction of multiplication problems correct in the 1-digit treatment and the 8-digit treatment. Then we conduct a median split of the data. We refer to the group whose multiplication scores are most diminished in the 8-digit treatment (as compared to the 1-digit treatment) as sensitive, and those whose multiplication scores are least affected by cognitive load as insensitive. ${ }^{11}$ We re-conducted the regression analysis for both groups separately. ${ }^{12}$ The results can be found in Table 4 for each task. Models 1b, 2b, $3 \mathrm{~b}$, and $4 \mathrm{~b}$ are for the insensitive subjects and Models $1 \mathrm{c}, 2 \mathrm{c}, 3 \mathrm{c}$, and $4 \mathrm{c}$ are for the sensitive subjects.

The split sample regression results indicate that the individuals for whom cognitive load affects arithmetic performance the most are the same people for whom cognitive load affects other behavior. In the Risk task, sensitive individuals are $7.1 \%$ less likely to take risk under cognitive load, a significant change. For the insensitive subjects, risk taking behavior is not different when memorizing a 1-digit or an 8-digit number. In the Anchoring task, the guesses of sensitive individuals increase by 0.159 units $(=0.094+0.065)$ for every unit increase in the anchor. Insensitive subjects are not affected. ${ }^{13}$ For the Impatience task, however, we again find an odd result. Recall that we found people become more patient under cognitive load. Those individuals whose multiplication performance is least affected by a large number are the most likely to become patient. This casts additional doubt to the hypothetical patience task and led us to conduct Experiment 2 which includes an incentivized Impatience task.

We also check how correctly recalling the number affects task performance when under cognitive load (see Figure A.2 of the Appendix). Participants have a much harder time recalling 8 -digit numbers (43\% recall rate) than they do recalling 1-digit numbers ( $96 \%$ recall rate). If a participant realizes that he or she has forgotten the number and no longer devotes

\footnotetext{
${ }^{11}$ Alternatively, it is possible to use a continuous measure of the performance drop in the multiplication task to define the level of overload sensitivity. Each method has its own strength. The median split is easy to interpret and assumes only a level difference in behavior across treatment. In contrast, the performance drop provides a potentially richer measure for overload sensitivity, while implicitly assuming that the performance varies linearly in the difference in multiplication scores. We have run the analysis both ways and the results do not change with the definition of sensitivity that was employed.

${ }^{12}$ Alternatively, we also conducted a difference-in-difference regression to test whether cognitive load sensitivity affects treatment effects. This method provides nearly identical results as the Hausman test described below.

${ }^{13}$ To test the difference between Model $2 \mathrm{~b}$ and $2 \mathrm{c}$ (as well as $3 \mathrm{~b}$ and $3 \mathrm{c} ; 4 \mathrm{~b}$ and $4 \mathrm{c}$ ), the simplest way is to use a generalized Hausman test to check whether the coefficient on 8-digit number is different across the two specifications. It is not different in the Risk task, the Impatience task, or the Anchoring task (Hausman $p$-value of $0.4442, p$-value of $0.3876, p$-value of 0.7037 respectively). Therefore we cannot conclude that the groups behave differently to the treatment. However, our results are suggestive that the overall effect is being driven by those who are overload sensitive.
} 
cognitive resources towards its memorization, then in effect, they are not under a cognitive load and their decision in the 8-digit task should resemble their decision in the 1-digit task. To test for this, we conduct regressions that not only test for the effect of receiving an 8-digit number, but also for the marginal effect of correctly recalling that number. Of course, we realize that those who can consistently recall an 8-digit number correctly may differ in their general abilities or attitudes in the main tasks than those who cannot. For that reason, we also include subject-fixed effects in our regressions. The results can be found in Table A.3 of the Appendix. ${ }^{14}$ These regressions also include sub-task-fixed effects and time-fixed effects for good measure; although their inclusion does not affect the significance of the results. For each of the four main tasks, those who correctly recalled the 8-digit number display an additional effect on behavior that is in the same direction as receiving the 8-digit number. However, except for the Risk task, we cannot significantly differentiate the mean difference in behavior of those receiving an 8-digit number, and those correctly recalling the 8-digit number.

We also examine how being in the 8-digit treatment affects the associated payoff in each task of the experiment. The results appear in Table A.4 of the Appendix. Payoffs noticeably decrease when individuals are in the 8-digit treatment. This effect is mainly driven by the reduced recall rates and the inability to accurately compute multiplication problems, but the remaining tasks contribute somewhat to the discrepancy as well. People in the 8-digit treatment actually made more money in the Risk task than those in the 1-digit treatment despite choosing the gamble less often. This is because on average, the gambles in the 8-digit treatment are more successful (55\%) than the gambles in the 1-digit treatment (45\%) due to random variation.

\section{Experiment 2}

Experiment 1 finds that, for a hypothetical time preference task, people who memorized larger numbers appear to be significantly more patient than those who memorize small numbers. Further examination indicates that it is the people least affected by the cognitive load manipulation who are responding in this way. We suspect this pattern is a result of participants ignoring the question and selecting the option that required the least physical and cognitive effort. Therefore, we conducted Experiment 2, which involved an intertemporal decision with real cash stakes. Experiment 2 also includes a intertemporal choice task over

\footnotetext{
${ }^{14}$ We checked for time effects. Subjects seem to display a trend towards improvement in each of the tasks, including the 8-digit number memorization task as time passes. However, there is no treatment-time interaction effect as the coefficient on Period $\times 8$-digit is zero.
} 
consumption where subjects chose between a small serving of a snack now and a larger serving in the future (e.g., 12 oz. package of M\&M's today vs. 19 oz. package of M\&M's in one week). Finally, Experiment 2 included two variations of the snack choice experiment of Shiv and Fedorikhin (1999). The choice was always between a healthy and unhealthy snack, and either the snack would be served that day, or the snack would be served the following week. ${ }^{15}$

\subsection{Methodology}

A total of 87 new subjects participated in Experiment 2. Similar to Experiment 1, in each period the participants observed a number to memorize, then made a decision, and were then asked to recall the memorized number. There were 51 periods and four types of possible decisions: (1) Money Impatience task, (2) Consumption Impatience task, (3) Immediate Snack Choice task, and (4) Delayed Snack Choice task.

Conducting an experiment with intertemporal choices and real stakes necessarily means that a subject may not be paid until some future date. If subjects view future payments to be more uncertain than immediate payments, then the measure of impatience will be intertwined with subjects' risk attitudes. In order to minimize uncertainty about future payments, participants in Experiment 2 were recruited for two sessions exactly one week apart. During recruitment subjects were told that the first session would take approximately one hour and pay a show-up fee of $\$ 5$, whereas the second session would take approximately 10 minutes and pay a show-up fee of $\$ 10$. Subjects made all of their decisions during the first session and the only purpose of the second session was so that subjects knew they would be returning to the laboratory one week later when making intertemporal choices during the first part of the experiment (all but one person actually returned one week later). Hence, all of the choices in Experiment 2 involved compensation collected either at the time the decision was made, or in exactly one week.

The Money Impatience task involved choices of the form $\$ X$ today or $\$ Y$ in one week. ${ }^{16}$ While most of the choices were such that $X<Y$, there were three choices for which $X>Y$;

\footnotetext{
${ }^{15}$ In the case of healthy and unhealthy snacks, the exact items used appear in Table A.5 in the Appendix. A number of different factors were considered when choosing the "healthy" and "unhealthy" food items. The number of calories contained in the item loomed large in the decision, but we also considered what items were readily available in case we needed to re-stock during the experiment, the size of the item so that it could easily be transported out of the experiment, and that the snacks were all in a similar price range.

${ }^{16}$ In our Money Impatience task, the immediate option was on average about $\$ 11$ whereas the next-week option was on average $\$ 11.75$. This implies a weekly discount factor of 0.936 . Under the standard model where people discount each period of time at a constant rate, this rate of discounting equates to a yearly discount factor of 0.032 . In other words, a person choosing the immediate option would be indifferent between having $\$ 100$ immediately or $\$ 95,000$ in two years.
} 
these served as verification questions to check the extent to which subjects were paying attention. ${ }^{17}$ The Consumption Impatience task offered subjects the binary choice of a small serving today or a larger serving in one week. Immediate Snack Choice tasks presented subjects with two food options - one healthy and one unhealthy - and the subject decided which they would rather have that day. Delayed Snack Choice tasks were similar, but the subject's selected snack was not provided until the following week. Shiv and Fedorikhin (1999) find that observing the actual food is an important factor affecting snack choice. Therefore, for the Immediate Snack Choice task, subjects were presented with the snack packages. For Delayed Snack Choice task, subjects were presented with pictures of the snack packages. For consistency across the four tasks, any item, including cash, that would be provided that day was presented physically while pictures were used for any item that would be provided in one week. Figure A.3 of the Appendix depicts sample images across each task; a full list of the options that participants faced can be found in Table A.5.

To facilitate presenting subjects with physical items, Experiment 2 was hand run instead of computerized as in Experiment 1. For this reason a single order of choices was predetermined randomly and then used for every subject. Hence every subject saw the same choice options in Experiment 2, which differs from Experiment 1, where tasks were randomly generated. During a session, seven to thirteen participants were seated at individual workstations with privacy dividers on either side but not to the front. In each period, an experimental assistant displayed a number to a participant for three seconds, after which the assistant moved to the next participant. Participants were asked to keep this number in their memory. Next, a second experimental assistant walked to the participant holding a tray displaying two options (physical items or pictures) and provided the participant a pen. The participant had to mark which of the two options they preferred. Finally, a third experimental assistant walked to the participant approximately 30 seconds after the first experimental assistant had, handed the subject a pen and asked them to recall the number that they were asked to memorize on a sheet of paper. The second and third assistants used different, non-traditional colored pens so that subjects could not record their memorized number before they were instructed to do so. ${ }^{18}$

As in Experiment 1, cognitive load was manipulated within-subject by varying the size of the number the participant had to memorize; however, in Experiment 2 subjects were shown either no number (0-digit number), a 2-digit number, or an 8-digit number. In part,

\footnotetext{
${ }^{17}$ More money today should be preferable to less money in the future. For these questions, we expected that nearly everybody chooses the earlier amount. We added these verification questions to make sure that subjects were attentive. If subjects relied on rules of thumb, such as "always choose the future payment," then their answers to these questions would deviate from our expectation.

${ }^{18} \mathrm{~A}$ video of this procedure is available upon request.
} 
this change from Experiment 1 was done for consistency with the snack choice experiments of Shiv and Fedorikhin (1999) and in part it was done to determine if even a small cognitive load would have an effect on decision making. A total of 8 sessions were run. For half of the sessions, participants were shown 8-digit numbers for the first 17 periods, no number for the next 17 periods, and 2-digit numbers for the last 17 periods. The order was reversed in the other half of the sessions so the two levels of cognitive load were always separated by the no cognitive load phase. If the subject recalled the number correctly or did not have a number to memorize, their memorization payoff for the period was $\$ 15$. The memorization payoff was smaller than in Experiment 1 because the duration of the experiment was shorter

Participants were paid for only one of their decisions, just as in Experiment 1. At the end of the experiment, each participant chose an index card labeled 1-51 that determined which of the 51 periods would be used to determine their compensation. The procedure of selecting a numbered card ensured that no two subjects in a session were owed the same product, thus limiting the inventory the researchers had to have on hand. Next, the experimenter randomly determined if the subject was to be compensated for the memorization task or the other task in the selected period. ${ }^{19}$

\subsection{Results}

We examine how a cognitive load manipulation affects subjects' choices in: (1) a Money Impatience task, (2) a Consumption Impatience task, (3) an Immediate Snack Choice task, and (4) a Delayed Snack Choice task. The data for each main task is presented separately. ${ }^{20}$

Table 5 presents the mean behavior in each decision task across the treatments (see Figure A.4 of the Appendix for a graphical representation). The outcomes for the three verification questions meant to check for attentiveness, are included at the bottom of the table, though we do not include these questions in any of the analysis that follows. The 0-digit treatment does not require a number to be memorized; the 2-digit treatment has a recall accuracy of $98.4 \%$ while the 8-digit treatment has a recall accuracy of $63.0 \%$ (difference $=35.4 \%, p$-value $<0.001$ using a two-sample unpaired t-test). Note that the recall rate for 8 -digit numbers in Experiment 2 is about 20 percentage points higher than it is in Experiment 1 (43.3\%), suggesting that participants may have viewed the tasks in Experiment 2 to be easier than those in Experiment 1.

OLS regressions were run to look at how behavior in the Money Impatience task, the

\footnotetext{
${ }^{19}$ This random process was done by rolling a standard 6 -sided die. If a 1, 2 or 3 was rolled, the subject was paid based on the memorization task; otherwise the subject was paid for the other task completed in the selected period.

${ }^{20} \mathrm{~A}$ breakdown of the results by sub-task can be found online at https://sites.google.com/site/salarj/research
} 
Table 5: Summary Table for Experiment 2.

\begin{tabular}{lccc}
\hline & 0-DIGIT & 2-Digit & 8-DIGIT \\
& \multicolumn{3}{c}{ Percentage } \\
& \multicolumn{3}{c}{ \# of Responses } \\
\hline Digit Memorization & - & $98.4 \%$ & $63.0 \%$ \\
& 1392 & 1392 & 1392 \\
\hline Took Early Option & $43.1 \%$ & $47.1 \%$ & $50.0 \%$ \\
for Money & 348 & 348 & 348 \\
\hline Took Early Option & $35.6 \%$ & $35.9 \%$ & $36.2 \%$ \\
for Consumption & 348 & 348 & 348 \\
\hline Chose Unhealthy & $54.3 \%$ & $56.3 \%$ & $56.3 \%$ \\
Option (today) & 348 & 348 & 348 \\
\hline Chose Unhealthy & $56.3 \%$ & $60.3 \%$ & $60.6 \%$ \\
Option (future) & 348 & 348 & 348 \\
\hline \hline Verification Questions (dropped from analysis) \\
Digit Memorization & $100 \%$ & $95.4 \%$ & $69.0 \%$ \\
& 87 & 87 & 87 \\
\hline Took Early Option & $100 \%$ & $93.1 \%$ & $93.1 \%$ \\
for Money & 87 & 87 & 87 \\
\hline
\end{tabular}




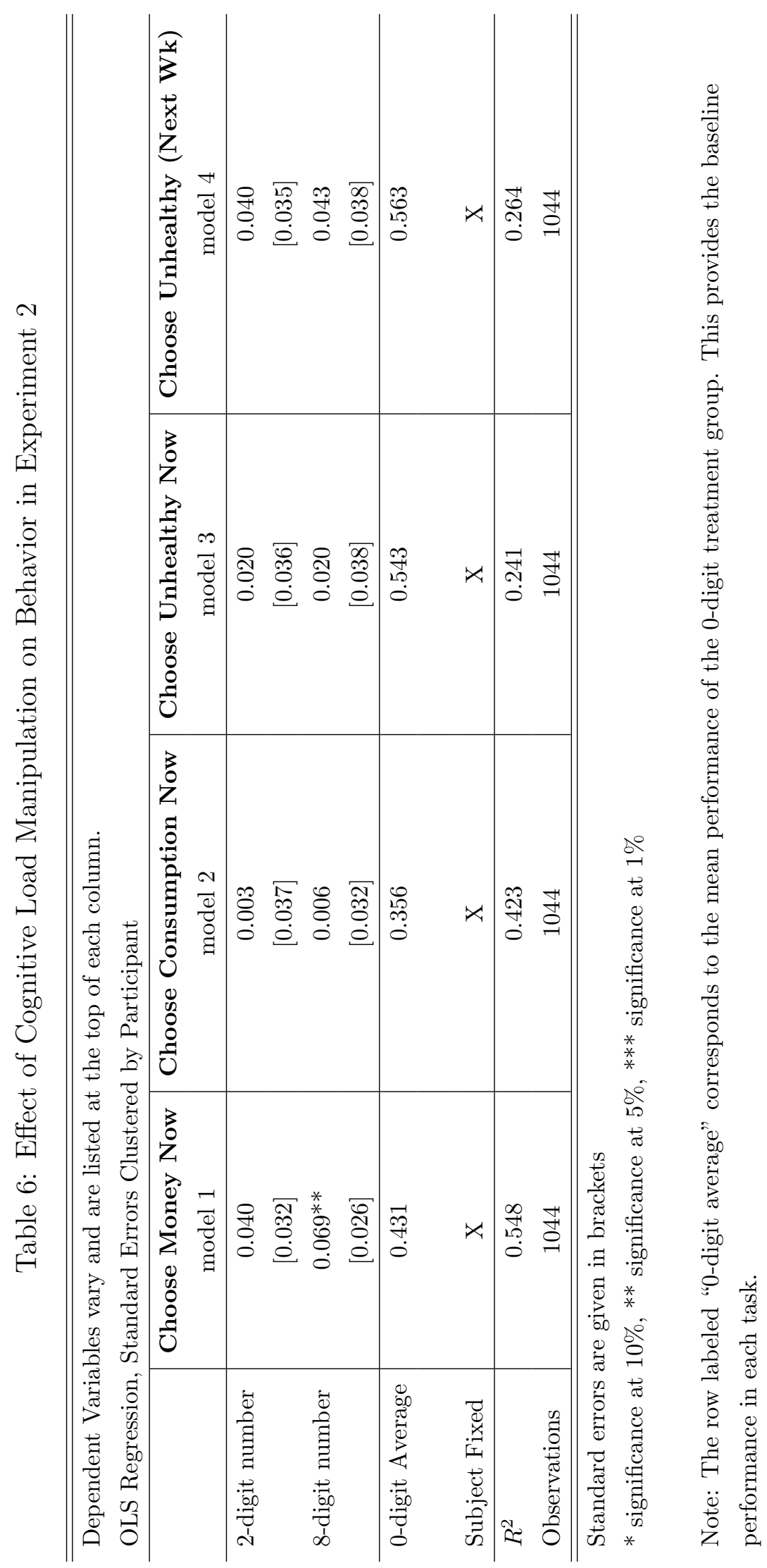


Consumption Impatience task, the Immediate Snack Choice task, and the Delayed Snack Choice task differed across the 0-digit, 2-digit, and 8-digit treatments. The regressions results in Table 6 include subject-fixed effects and have standard errors clustered by participant. The results are in line with the summary statistics listed in Table 5: cognitive load only affects behavior in the Money Impatience task. The results from a Wald test indicate that those in the 8-digit treatment chose the impatient outcome 6.9\% more often $(p=0.010)$ than those with no number memorization task. There is no statistical difference in the choice of the impatient option between the 2-digit and 8-digit treatments $(p=0.397)$. The results do not change substantively when the analysis is conducted using probit regressions (see Table A.6 of the Appendix).

For the Consumption Impatience task, it is apparent that there is no noticeable difference in the mean behavior of those memorizing 0-digit, 2-digit, and 8-digit numbers. Regardless of digit length, about $36 \%$ of participants chose the less-consumption-today option. While one might expect individuals to behave more impatiently for consumption goods than for monetary goods, we do not find this to be the case in our study. We believe, however, that this might be due to the mechanics of package size differences for products in the experiment. For the consumption goods, the size of the immediate consumption bundle was on average $69 \%$ smaller than the size of the future consumption bundle; this represents a much greater rate of return than in the cash tasks where the average difference was only $6 \%$. This difference in package size was probably so large that participants likely felt a strong preference for either the small or large bundle. With strong enough preferences, cognitive load is unlikely to sway behavior.

For the remaining two tasks, each involving the choice between a healthy and unhealthy snack, the mean difference in behavior across treatments indicates that memorizing a number of any-length increased the likelihood of choosing the unhealthy option, but not significantly so. In the Immediate Snack Choice task, subjects chose $2 \%$ more unhealthy snacks in the 2-digit and 8-digit treatment as compared to the 0-digit treatment. However, even when the 2-digit and 8-digit treatments are pooled and the regression is rerun, a Wald test fails to find a significant difference in behavior across those treatments and the 0-digit treatment $(p=0.533)$. In the Delayed Snack Choice task, subjects chose $4 \%$ more unhealthy snacks in the 2-digit and 8-digit treatment as compared to the 0-digit treatment. This result is not significant: a similar Wald test rejects a difference between the no-memorization and memorization treatments $(p=0.199)$. In fact, we fail to replicate the finding that digitmemorization increases unhealthy snack choice. Indeed, even if we pool the data from the Immediate and Delayed Snack Choice tasks together (so that we have 2088 snack choice 
decisions $)^{21}$ and test for a difference between no memorization vs. any digit-memorization - which gives us the strongest chance of finding a result - we find no significant difference (difference $=0.031$, Wald test $p$-value $=0.197$ )

We do not find evidence that performance in each task varied over the course of the experiment. Table A.7 of the Appendix reports results of nine OLS regressions run for each task on the following segments of data: periods 1-17, periods 18-34, and periods 3551. ${ }^{22}$ Data for Immediate and Delayed Snack Choice tasks are pooled for power, but there does not appear to be any differential effect from memorizing numbers across time for any of the tasks. Interestingly however, people do seem to exhibit more patience in both the Money Impatience task and the Consumption Impatience task as the experiment progresses (the constant term is decreasing). A generalized Hausman specification test rejects the hypothesis that the Constant parameter is equal across the three time periods $(p=0.014)$ in the Money Impatience task. For the Consumption Impatience task, people are also less likely to choose the patient option as the experiment progress but not significantly across treatments (Hausman $p=0.359$ ). There is a non-significant trend to choose more unhealthy snacks over time (Hausman $p=0.188$ ).

Overall, there does not seem to be much of an effect from being assigned a 2-digit or 8-digit number when it comes to food choice although people are more impatient for money when subjected to an increased cognitive load.

\section{Conclusion}

This paper looks at the effect of cognitive load on economic decision making. A survey of the existing literature suggests that people typically make poorer decisions across a variety of situations when subjected to increased levels of cognitive load. Our review describes the findings of studies where cognitive load is imposed through a memorization task, but comparability is still challenging given the array of methodologies that are used and the fact that most studies only examine behavior in a single task.

In a series of experimental studies, we employ a standardized format that tests for the effect of cognitive load on multiple economic tasks at once. We find that memorizing longer numbers is associated with worse performance on arithmetic questions, less risk-taking, higher susceptibility to anchoring effects, and more impatience for money when the choice is for real stakes. We do not find any evidence that cognitive load increases impatience as

\footnotetext{
${ }^{21}$ In contrast, Shiv and Fedorikhin (1999) who identify the effect, do so with about 80 observations.

${ }^{22}$ There does not seem to be much learning occurring. In addition to splitting the data into three equal parts, we also included a (period x 8-digit) interaction term for each of the four tasks as a robustness check. The estimated coefficient for this interaction was 0.00 for each of the tasks.
} 
measured by selecting unhealthy snacks over healthy snacks in contrast with some of the earlier findings in the literature. The results that we attain are generally consistent with the findings from other studies that look at the effect of cognitive load on specific decision making (see Table 1) though the magnitude of our effects are typically smaller than those found in psychology studies.

Studies that only look at how cognitive load affects risk-taking (Gerhardt, 2013) or affects impatience (Getz, 2013) cannot take a stand on whether cognitive load leads to better or worse decisions nor can they determine if people who are most affected by cognitive load on one type of task are the same people who are most affected by cognitive load in a different type of task. Like Benjamin et al. (2013) we include arithmetic questions as one of the decision tasks. Arithmetic questions have a verifiable correct answer, a feature that allows us to objectively determine whether people are being affected by cognitive load. While the manipulation in Benjamin et al. (2013) did not affect quantitative performance, our manipulation did, suggesting that our subjects were under cognitive load when making other types of decisions. Further, we find that those individuals whose arithmetic performance is most affected by cognitive load are the same individuals who become more risk averse and more impacted by anchoring when under increased cognitive load. This provides strong evidence that cognitive load is fundamentally harming an individual's ability to effectively make choices.

Our findings are in line with many of the predictions of dual-system theory (Loewenstein and O'Donoghue, 2004; Fudenberg and Levine, 2006), ${ }^{23}$ yet more research is necessary to pinpoint the exact mechanism by which cognitive load impairs choice. One possibility is that cognitive load simply generates more random choices rather than pushing preferences towards impulsive behavior (Franco-Watkins et al., 2006; Andersson et al., 2013). Indeed, in our experiment, aggregate behavior in the Risk and Money Impatience tasks can be interpreted as being 'more random' under cognitive load - in both tasks on aggregate, behavior in the

\footnotetext{
${ }^{23}$ In Loewenstein and ODonoghue (2004), the two systems are referred to as the affective and deliberate systems whereas in Fudenberg and Levine (2006), the systems are referred to as short-run and long-run selves. Depending on the way the models are structured, each can generate predictions that can explain our findings. The main application of the costly self-control model proposed by the Fudenberg and Levine is to explain time-inconsistent choice and preference for commitment devices. It is true that it can explain the effects of cognitive load on impatience but additional assumptions have to be made; even further assumptions need to be made to predict how cognitive load might cause people to be more risk-averse. The Loewenstein and ODonoghue model, on the other hand, has a natural explanation as to how cognitive load affects behavior. In their model, they hypothesize that deliberation occurs in the pre-frontal cortex, the same part of the brain that is responsible for "working memory." Requiring subjects to hold information in their mind for a short period of time diminishes the performance of the pre-frontal cortex, allowing for the affective system to dominate the decisionmaking process. Insofar as small-scale risk-aversion and short-run impatience are intuitive decisions that the deliberative system eventually overrides, then cognitive load will lead to more of such phenomenon.
} 
8-digit is closer to $50 \%$ (random choice) than in the 1-digit treatment. It should be noted, however, that an implication of random choice is that people will be less consistent across their choices. Given that we have repeated observations from each individual under different levels of cognitive load, we can test the level of internal consistency among individual's choices. People do not appear less consistent under cognitive load - indicating the results are not driven by randomness. Indeed, in just as many situations, aggregate choices seem to move away from the prediction of randomness.

Consider the Money Impatience task. Every choice to wait for a larger future payment generates a lower bound on the person's discount factor whereas each choice to take money immediately generates an upper bound on the discount factor. We categorize a person as 'consistent' under a given cognitive load if there exists a discount factor that simultaneously satisfies all of the implied bounds from their decisions. Given that there are four Money Impatience tasks, there are 16 total ways a subject could respond - only five of those are considered consistent. Overall we observe that $76 \%, 82 \%$, and $85 \%$ of subjects are consistent when memorizing 0-digit, 2-digit, and 8-digit numbers, respectively. Nominally, memorizing a larger number is associated with less random behavior on the Money Impatience task. Furthermore, for the verification questions in the 2- and 8-digit cases, it was rare for anybody to select having less money in the future, even though random selection would have implied they choose this option $50 \%$ of the time. Likewise, we observed no change in healthy versus unhealthy snack choice based on treatment. Therefore, we are fairly confident the impact of cognitive load that we observe is not due to randomness.

A similar exercise can be done for the Risk task in the gain domain. ${ }^{24}$ We find that there exists some risk parameter value calculated under constant relative risk aversion that is consistent with their choices for $54 \%$ of subjects when memorizing a 1-digit number in the gain domain. We find the exact same percent to be consistent when memorizing an 8-digit number in the gain domain. This indicates that behavior is not simply due to more random behavior under cognitive load, similar to Gerhardt (2013). We also note that anchoring was found to be greater when people were under cognitive load, whereas random behavior would imply that anchors should have less of an effect.

An obvious implication of our study is that many important economic parameters such as risk, impatience, and anchoring are not stable and that they vary within-person as one's cognitive load changes. The same person who appears very patient when they are under no cognitive load could appear quite impatient when their mind is occupied. This withinperson difference in behavior for the same economic activity raises the question of whether

\footnotetext{
${ }^{24}$ For risks in the loss domain, behavior moves away from randomness (away from $50 \%$ ) in aggregate when individuals face higher cognitive load.
} 
we should consider actions such as avoiding risk taking as representing a preference or a potential mistake. More research is needed to thoughtfully answer this question. 


\section{References}

[1] Abaluck, Jason, and Jonathan Gruber. "Choice Inconsistencies Among the Elderly: Evidence from Plan Choice in the Medicare Part D Program." American Economic Review (2011): 1180-1210.

[2] Allred, Sarah, Sean Duffy, and John Smith. "Cognitive Load and Strategic Sophistication." Rutgers University-Camden, Working paper (2015a).

[3] Allred, Sarah, Crawford L Elizabeth, Duffy Sean, and Smith John. "Working Memory and Spatial Judgments: Cognitive Load Increases the Central Tendency Bias." Rutgers University-Camden, Working paper (2015b).

[4] Andersson, Ola, Jean-Robert Tyran, Erik Wengström, and Håkan J. Holm. "Risk Aversion Relates to Cognitive Ability: Fact or Fiction?" IFN Working Paper No. 964 (2013).

[5] Beauchamp, Jonathan, David Cesarini, and Magnus Johannesson. "The Psychometric Properties of Measures of Economic Risk Preferences." New York University, Working Paper (2012).

[6] Benjamin, Daniel, Sebastian Brown, and Jesse Shapiro. "Who is 'Behavioral'? Cognitive Ability and Anomalous Preferences." Journal of the European Economic Association 11(6), (2013): 1231-1255.

[7] Bergman, Oscar, Tore Ellingsen, Magnus Johannesson, and Cicek Svensson. "Anchoring and Cognitive Ability." Economics Letters 107(1), (2010): 66-68.

[8] Besedeš, Tibor, Cary Deck, Sudipta Sarangi, and Mikhael Shor. "Age Effects and Heuristics in Decision Making." Review of Economics and Statistics 94(2), (2012): 580595.

[9] Besedeš, Tibor, Cary Deck, Sudipta Sarangi, and Mikhael Shor. "Reducing Choice Overload without Reducing Choices." Review of Economics and Statistics (forthcoming).

[10] Block, Richard A., Peter A. Hancock, and Dan Zakay. "How Cognitive Load Affects Duration Judgment: A Meta-Analytic Review." Acta Psychologica 134(3), (2010): 330343.

[11] Burks, Stephen V., Jeffrey P. Carpenter, Lorenz Goette, and Aldo Rustichini. "Cognitive Skills Affect Economic Preferences, Strategic Behavior, and Job Attachment." Proceedings of the National Academy of Sciences 106(19), (2009): 7745-7750. 
[12] Butler, Jeff, Luigi Guiso, and Tullio Jappelli. "Manipulating Reliance on Intuition Reduces Risk and Ambiguity Aversion." Centre for Economic Policy Research, Working Paper (2013).

[13] Cappelletti, Dominique, Werner Guth, and Matteo Ploner. "Being of Two Minds: Ultimatum Offers Under Cognitive Constraints." Journal of Economic Psychology 32(6), (2011): 940-950.

[14] Carpenter, Jeffrey, Michael Graham, and Jesse Wolf. "Cognitive Ability and Strategic Sophistication." Games and Economic Behavior 80 (2013): 115-130.

[15] Chen, Chia-Ching, I. Chiu, John Smith, and Tetsuji Yamada. "Too Smart to be Selfish? Measures of Cognitive Ability, Social Preferences, and Consistency." Journal of Economic Behavior and Organization 90 (2013): 112-122.

[16] Corazzini, Luca, Antonio Filippin, and Paolo Vanin. "Economic Behavior under Alcohol Influence: An Experiment on Time, Risk, and Social Preferences." Universita di Bologna, Working Paper (2014).

[17] Cornelissen, Gert, Siegfried Dewitte, Luk Warlop and Vincent Yzerbyt. "Whatever People Say I Am, That's What I am: Social Labeling as a Social Marketing Tool." International Journal of Research in Marketing (2007): 278-288.

[18] De Neys, Wim. "Dual Processing in Reasoning: Two Systems but One Reasoner." Psychological Science 17(5), (2006): 428-433.

[19] Deck, Cary, and Salar Jahedi. "An Experimental Investigation of Time Discounting in Strategic Settings" Journal of Behavioral and Experimental Economics 54, (February 2015a): 95-104.

[20] Deck, Cary, and Salar Jahedi. "Time Discounting in Strategic Contests." Journal of Economics and Management Strategy 24(1), (February 2015b): 151-164.

[21] Dohmen, Thomas, Armin Falk, David Huffman, and Uwe Sunde. "Are Risk Aversion and Impatience Related to Cognitive Ability?" American Economic Review 100(3), (2010): 1238-60.

[22] Duffy, Sean, and John Smith. "Cognitive Load in the Multi-player Prisoner's Dilemma Game: Are there Brains in Games?" Journal of Behavioral and Experimental Economics 51 (2014): 47-56. 
[23] Fischbacher, Urs. "z-Tree: Zurich Toolbox for Ready-made Economic Experiments." Experimental Economics 10(2), (2007): 171-178.

[24] Franco-Watkins, Ana M., Harold Pashler, and Timothy C. Rickard. "Does Working Memory Load Lead to Greater Impulsivity? Commentary on Hinson, Jameson, and Whitney (2003)." Journal of Experimental Psychology: Learning, Memory, and Cognition 32(2), (2006): 443-447.

[25] Franco-Watkins, Ana M., Timothy C. Rickard, and Hal Pashler. "Taxing Executive Processes Does Not Necessarily Increase Impulsive Decision Making." Experimental Psychology 57(3), (2010): 193-201.

[26] Frederick, Shane. "Cognitive Reflection and Decision Making." Journal of Economic Perspectives 19(4), (2005): 25-42.

[27] Fudenberg, Drew and David K. Levine. "A Dual-Self Model of Impulse Control." American Economic Review 96(5), (2006): 1449-1476.

[28] Gerhardt, Holger. "Essays in Experimental and Neuroeconomics." Humboldt University of Berlin, PhD Dissertation (2013).

[29] Getz, Sarah Jean. "Cognitive Control and Intertemporal Choice: The Role of Cognitive Control in Impulsive Decision Making." Princeton University, PhD Dissertation (2013).

[30] Gilbert, Daniel T., Brett W. Pelham, and Douglas S. Krull. "On Cognitive Busyness: When Person Perceivers Meet Persons Perceived." Journal of Personality and Social Psychology 54(5), (1988): 733.

[31] Greene, Joshua D., Sylvia A. Morelli, Kelly Lowenberg, Leigh E. Nystrom, and Jonathan D. Cohen. "Cognitive Load Selectively Interferes with Utilitarian Moral Judgment." Cognition 107(3), (2008): 1144-1154.

[32] Hauge, Karen Evelyn, Kejll Arne Brekke, Lars-Olof Johansson, Olof JohanssonStenman, and Henrik Svedsater. "Keeping Others in Our Mind or in Our Heart? Distribution Games under Cognitive Load." University of Gothenburg, Working paper (2014).

[33] Hinson, John M., Tina L. Jameson, and Paul Whitney. "Impulsive Decision Making and Working Memory." Journal of Experimental Psychology: Learning, Memory, and Cognition 29(2), (2003): 298-306. 
[34] Iyengar, Sheena S., Gur Huberman, and Wei Jiang. "How Much Choice is Too Much? Contributions to 401(k) Retirement Plans." Pension Design and Structure: New Lessons from Behavioral Finance (2004): 83-95.

[35] Kahneman, Daniel. "Maps of Bounded Rationality: A Perspective on Intuitive Judgment and Choice." Nobel Prize Lecture, Dec 8 2002: 351-401. see http://www.nobelprize.org/nobel_prizes/economic-sciences/laureates/2002/ kahnemann-lecture.pdf

[36] Kahneman, Daniel. Thinking, Fast and Slow. Farrar, Straus and Giroux, 2011.

[37] Köszegi, Botond, and Matthew Rabin. "A Model of Reference-Dependent Preferences." Quarterly Journal of Economics 121(4), (2006): 1133-1165.

[38] Laibson, David. "Golden Eggs and Hyperbolic Discounting." Quarterly Journal of Economics 112(2), (1997): 443-477.

[39] Loewenstein, George, and Ted O’Donoghue. "Animal Spirits: Affective and Deliberative Processes in Economic Behavior." Available at SSRN 539843 (2004).

[40] Mani, Anandi, Sendhil Mullainathan, Eldar Shafir, and Jiaying Zhao. "Poverty Impedes Cognitive Function." Science, 341(6149), (2013): 976-980.

[41] McKenna, Benjamin S., David L. Dickinson, Henry J. Orff, and Sean Drummond. "The Effects of One Night of Sleep Deprivation on Known-Risk and Ambiguous-Risk Decisions." Journal of Sleep Research 16(3), (2007): 245-252.

[42] Milinski, Manfred, and Claus Wedekind. "Working Memory Constrains Human Cooperation in the Prisoner's Dilemma." Proceedings of the National Academy of Sciences (1998): 13755-13758.

[43] Miller, George A. "The Magic Number Seven Plus or Minus Two: Some Limits on our Capacity to Process Information." Psychological Review 63(2), (1956): 81.

[44] Mukherjee, Kanchan. "A Dual System Model of Preferences Under Risk." Psychological Review 117 (2010): 243-255.

[45] Oechssler, Jorg, Andreas Roider, and Patrick W. Schmitz. "Cognitive Abilities and Behavioral Biases." Journal of Economic Behavior and Organization 72(1), (2009): 147152. 
[46] Rand, David G., Joshua D. Greene, and Martin A. Nowak. "Spontaneous Giving and Calculated Greed." Nature 489(7416), (2012): 427-430.

[47] Roch, Sylvia G., John AS Lane, Charles D. Samuelson, Scott T. Allison, and Jennifer L. Dent. "Cognitive Load and the Equality Heuristic: a Two-stage Model of Resource Overconsumption in Small Groups." Organizational Behavior and Human Decision Processes 83(2), (2000): 185-212.

[48] Rydval, Ondrej. "The Causal Effect of Cognitive Abilities on Economic Behavior: Evidence from a Forecasting Task with Varying Cognitive Load." University of Jena, Working Paper (2011).

[49] Schram, Arthur, and Joep Sonnemans. "How Individuals Choose Health Insurance: An Experimental Analysis." European Economic Review 55(6) (2011): 799-819.

[50] Schulz, Jonathan F., Urs Fischbacher, Christian Thoni, and Verena Utikal. "Affect and Fairness: Dictator Games Under Cognitive Load." Journal of Economic Psychology 41 (2014): 77-87.

[51] Shamosh, Noah A., and Jeremy R. Gray. "Delay Discounting and Intelligence: A MetaAnalysis." Intelligence 36(4), (2008): 289-305.

[52] Shiv, Baba, and Alexander Fedorikhin. "Heart and Mind in Conflict: The Interplay of Affect and Cognition in Consumer Decision Making." Journal of Consumer Research 26(3), (1999): 278-292.

[53] Sprenger, Amber M., Michael R. Dougherty, Sharona M. Atkins, Ana M. FrancoWatkins, Rick P. Thomas, Nicholas Lange, and Brandon Abbs. "Implications of Cognitive Load for Hypothesis Generation and Probability Judgment." Frontiers in Psychology 2 (2011): 1-15.

[54] Tversky, Amos, and Daniel Kahneman. "Judgment Under Uncertainty: Heuristics and Biases." Science 185(4157), (1974): 1124-1131.

[55] Tversky, Amos, and Itamar Simonson. "Context-Dependent Preferences." Management Science 39(10), (1993): 1179-1189.

[56] Van den Bos, Kees, Susanne L. Peters, D. Ramona Bobocel, and Jan Fekke Ybema. "On Preferences and Doing the Right Thing: Satisfaction with Advantageous Inequity when Cognitive Processing is Limited." Journal of Experimental Social Psychology 42(3), (2006): 273-289. 
[57] Van Boven, Leaf, and Michael D. Robinson. "Boys Don't Cry: Cognitive Load and Priming Increase Stereotypic Sex Difference in Emotion Memory." Journal of Experimental Social Psychology 48(1), (2012): 303-309.

[58] Ward, Andrew, and Traci Mann. "Don't Mind If I Do: Disinhibited Eating Under Cognitive Load." Journal of Personality and Social Psychology 78(4), (2000): 753-763.

[59] Whitney, Paul, Christa A. Rinehart, and John M. Hinson. "Framing Effects Under Cognitive Load: The Role of Working Memory in Risky Decisions." Psychonomic Bulletin E3 Review 15(6), (2008): 1179-1184.

[60] Zimmerman, Frederick J., and Sandhya V. Shimoga. "The Effects of Food Advertising and Cognitive Load on Food Choices." BMC Public Health 14(1), (2014): 342. 
Appendix 


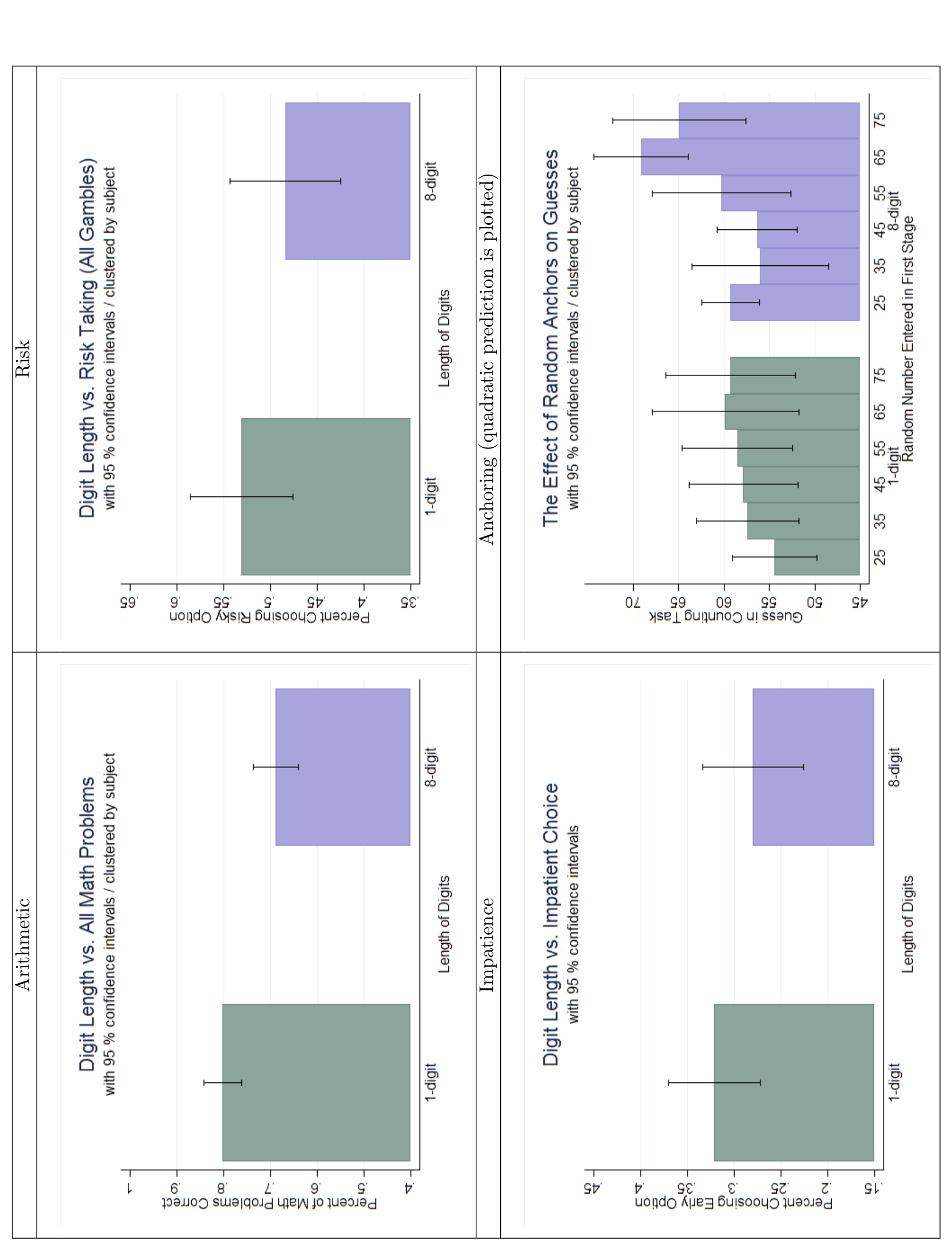

$\stackrel{8}{\square}$

이

ப்

है

흐 㐘

인

$\stackrel{0}{2}$

บ

ठั

os

융

ठ․

ত

需

क 0

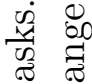

I

当

घ

Ð0

닝

की

엉

중

으

.

.

80

$4+$

$+2$

幽

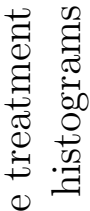

E

$\ddot{-}$

य. 


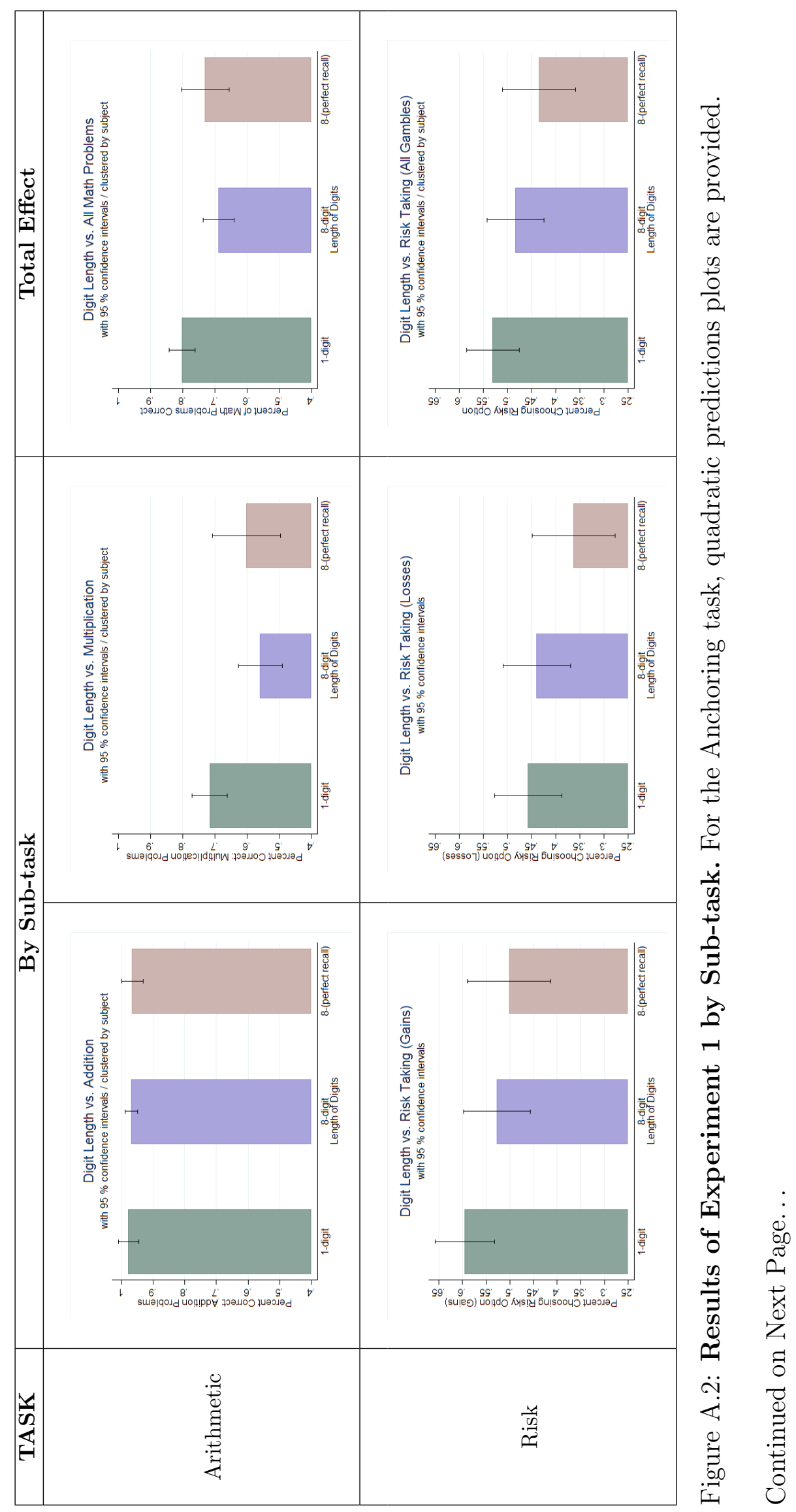




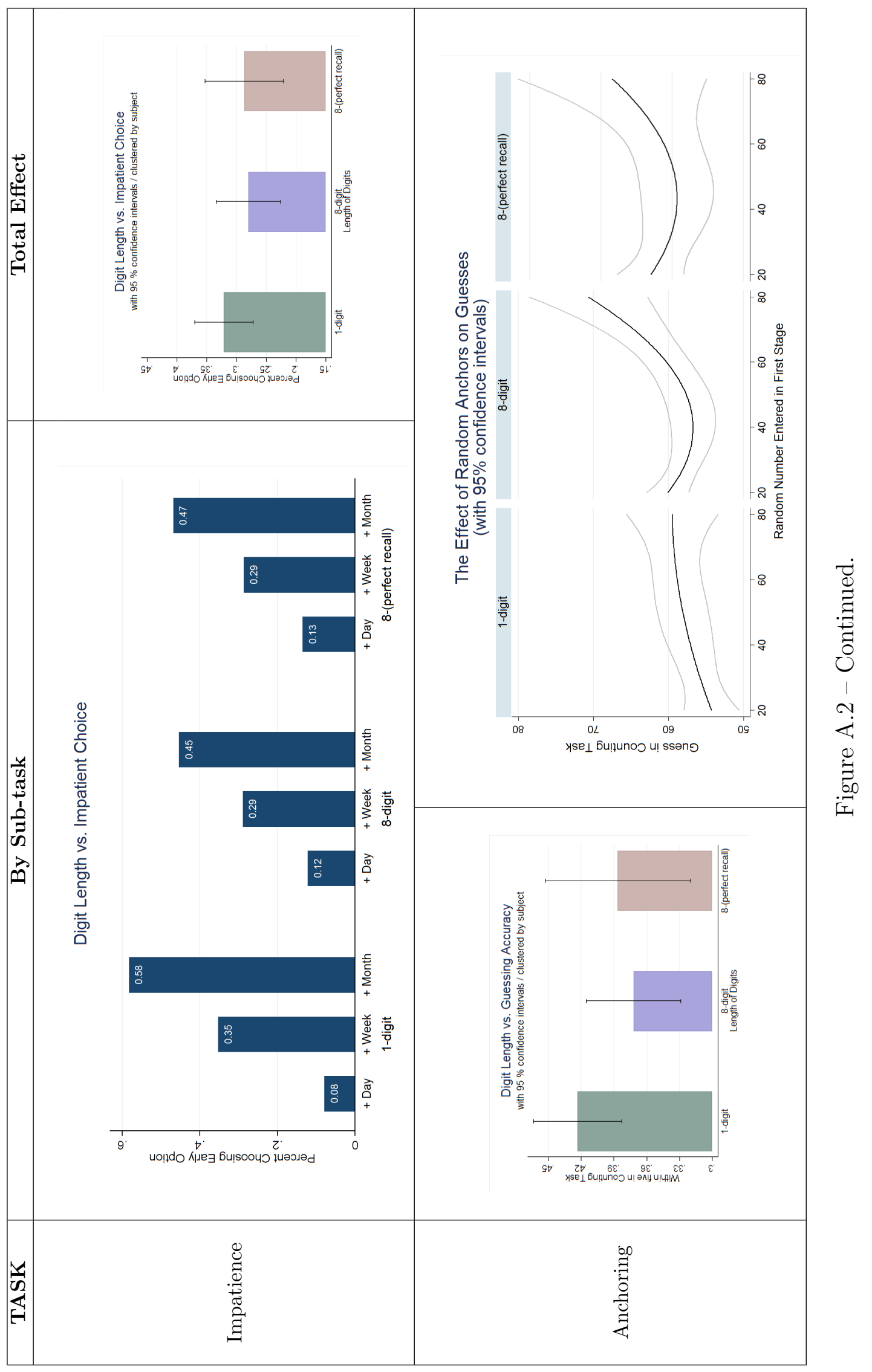




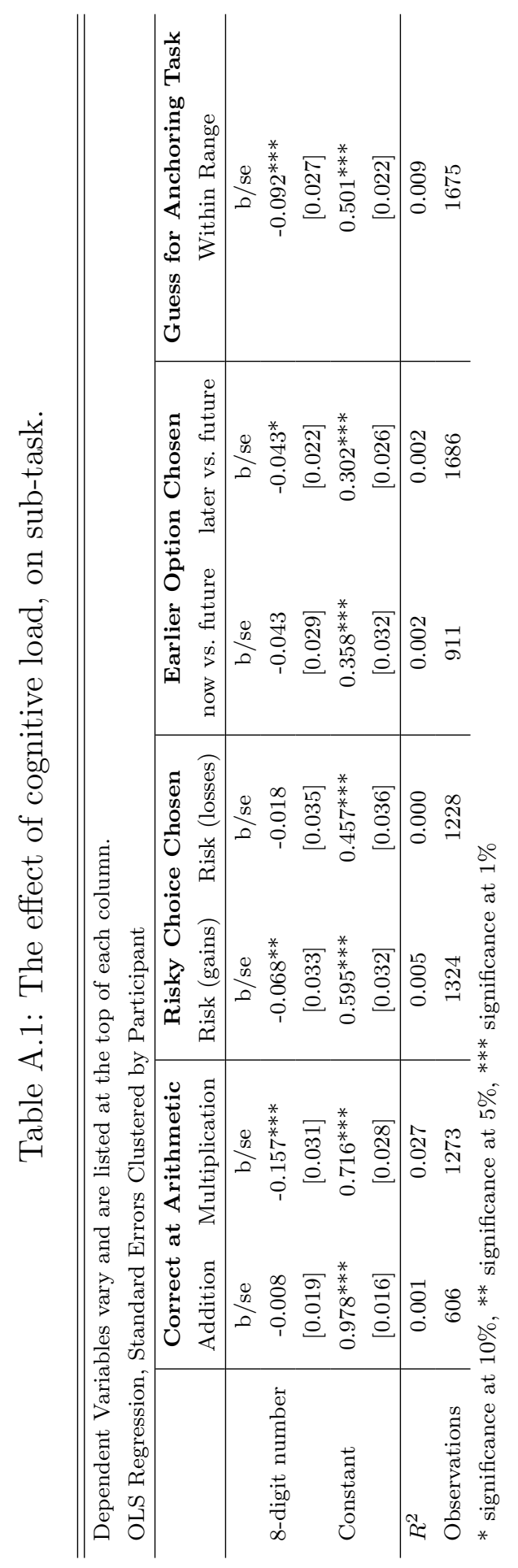




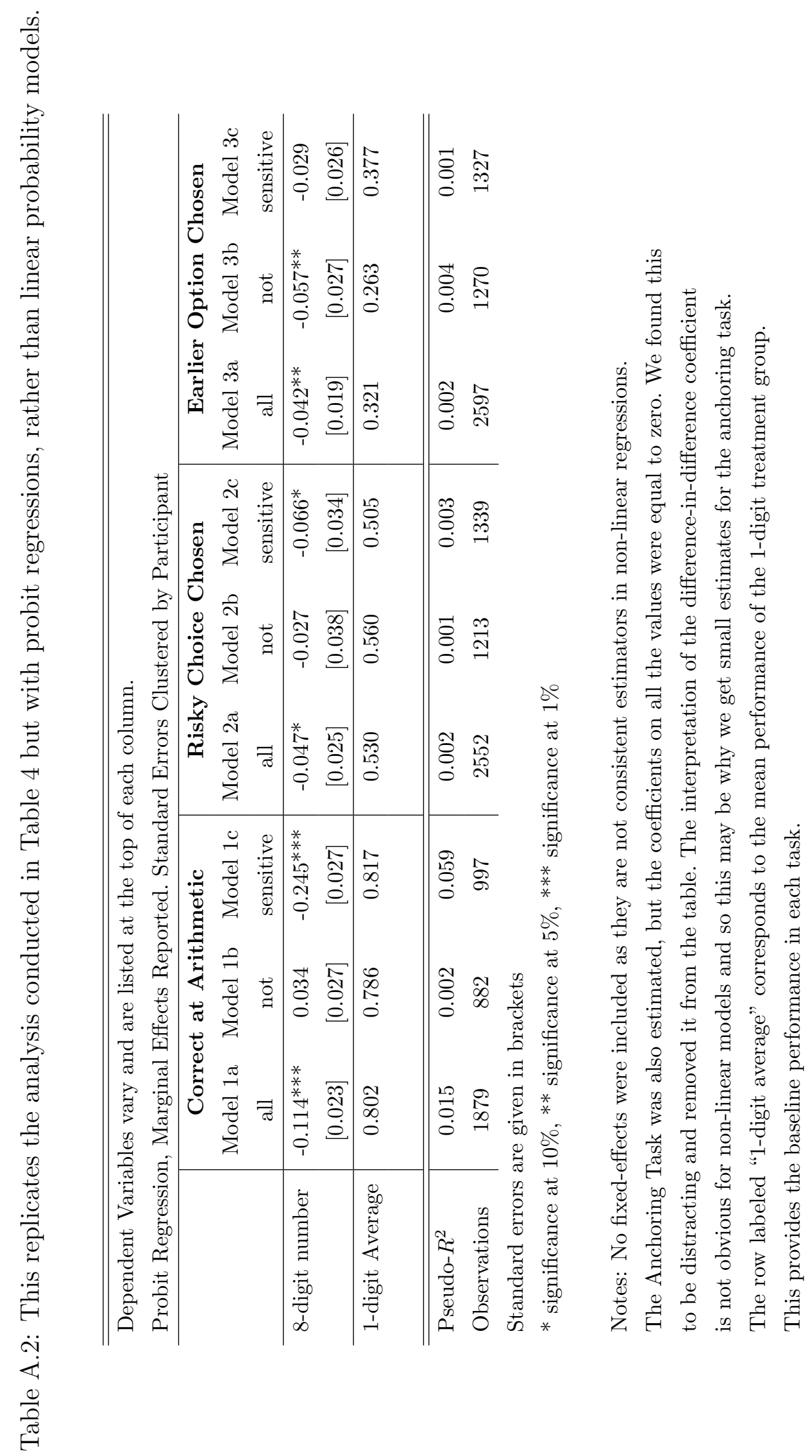




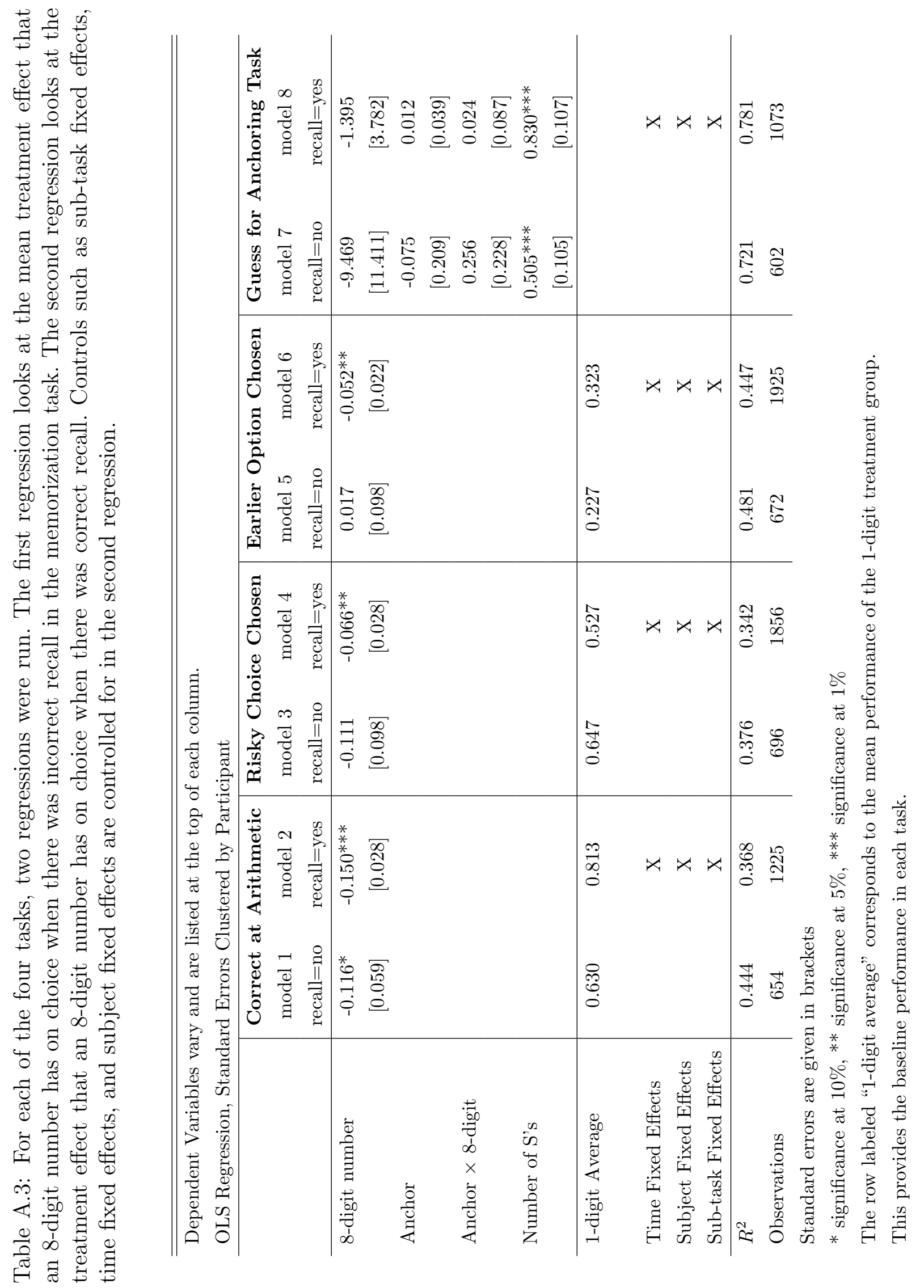


Table A.4: The average payoff by main task are shown below.

\begin{tabular}{|c|c|c|c|}
\hline \multicolumn{4}{|c|}{ Experiment 1} \\
\hline & & 1-digit & 8-digit \\
\hline \multirow{2}{*}{\multicolumn{2}{|c|}{ Number Memorization }} & $\$ 21.19$ & $\$ 9.52$ \\
\hline & & {$[0.62]$} & {$[0.16]$} \\
\hline \multirow{2}{*}{\multicolumn{2}{|c|}{ Math (addition) }} & $\$ 11.73$ & $\$ 11.63$ \\
\hline & & {$[0.10]$} & {$[0.12]$} \\
\hline \multirow{2}{*}{\multicolumn{2}{|c|}{ Math (multiplication) }} & $\$ 8.59$ & $\$ 6.70$ \\
\hline & & {$[0.22]$} & {$[0.24]$} \\
\hline \multirow{2}{*}{\multicolumn{2}{|c|}{ Risk (gains) }} & $\$ 11.57$ & $\$ 12.43$ \\
\hline & & {$[0.32]$} & {$[0.31]$} \\
\hline \multirow{2}{*}{\multicolumn{2}{|c|}{ Risk (losses) }} & $\$ 12.03$ & $\$ 11.89$ \\
\hline & & {$[0.32]$} & {$[0.30]$} \\
\hline \multirow{2}{*}{\multicolumn{2}{|c|}{ Impatience }} & $\$ 12.00$ & $\$ 12.00$ \\
\hline & & {$[0.00]$} & {$[0.00]$} \\
\hline \multirow{2}{*}{\multicolumn{2}{|c|}{ Anchoring }} & $\$ 5.08$ & $\$ 4.46$ \\
\hline & & {$[0.19]$} & {$[0.19]$} \\
\hline \multicolumn{4}{|c|}{ Experiment 2} \\
\hline & 0 -digit & 2-digit & 8-digit \\
\hline \multirow[t]{2}{*}{ Number Memorization } & $\$ 15.00$ & $\$ 14.76$ & $\$ 9.45$ \\
\hline & {$[0.00]$} & {$[0.05]$} & {$[0.19]$} \\
\hline \multirow[t]{2}{*}{ Money Impatience } & $\$ 11.02$ & $\$ 11.69$ & $\$ 11.66$ \\
\hline & {$[0.88]$} & {$[1.12]$} & {$[1.14]$} \\
\hline Consumption Impatience & $\begin{array}{c}1430 \text { kcal } \\
{[971]}\end{array}$ & $\begin{array}{c}1461 \mathrm{kcal} \\
{[791]}\end{array}$ & $\begin{array}{c}1528 \mathrm{kcal} \\
{[771]}\end{array}$ \\
\hline Immediate Snack Choice & $\begin{array}{c}1505 \text { kcal } \\
{[394]}\end{array}$ & $\begin{array}{c}1772 \text { kcal } \\
{[1534]}\end{array}$ & $\begin{array}{c}1623 \mathrm{kcal} \\
{[1378]}\end{array}$ \\
\hline Delayed Snack Choice & $\begin{array}{c}1291 \mathrm{kcal} \\
{[765]}\end{array}$ & $\begin{array}{c}1253 \mathrm{kcal} \\
{[382]}\end{array}$ & $\begin{array}{c}1255 \mathrm{kcal} \\
{[387]}\end{array}$ \\
\hline
\end{tabular}




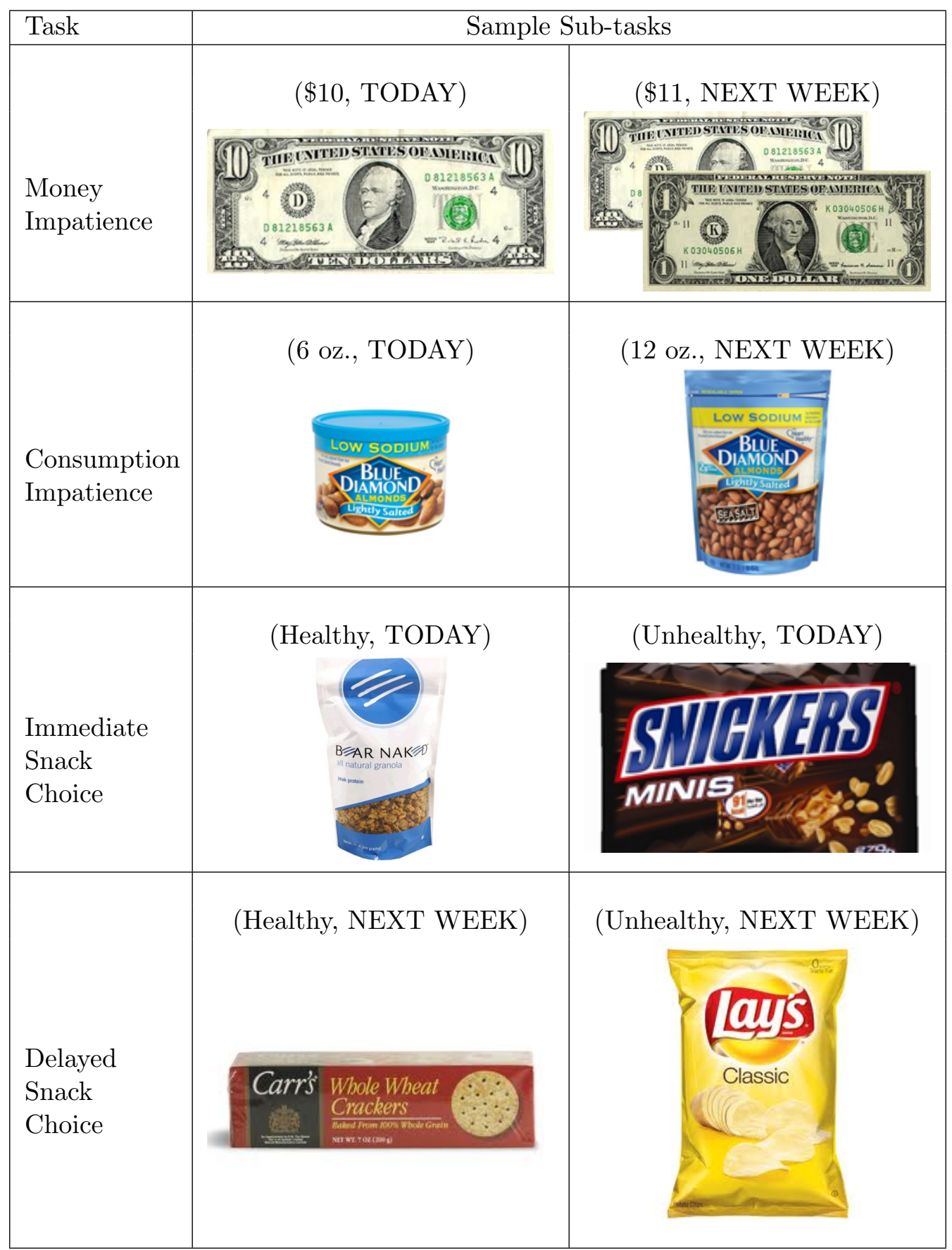

Figure A.3: Sample Tasks in Experiment 2. TODAY items were physically displayed whereas NEXT WEEK items were depicted by a picture. 


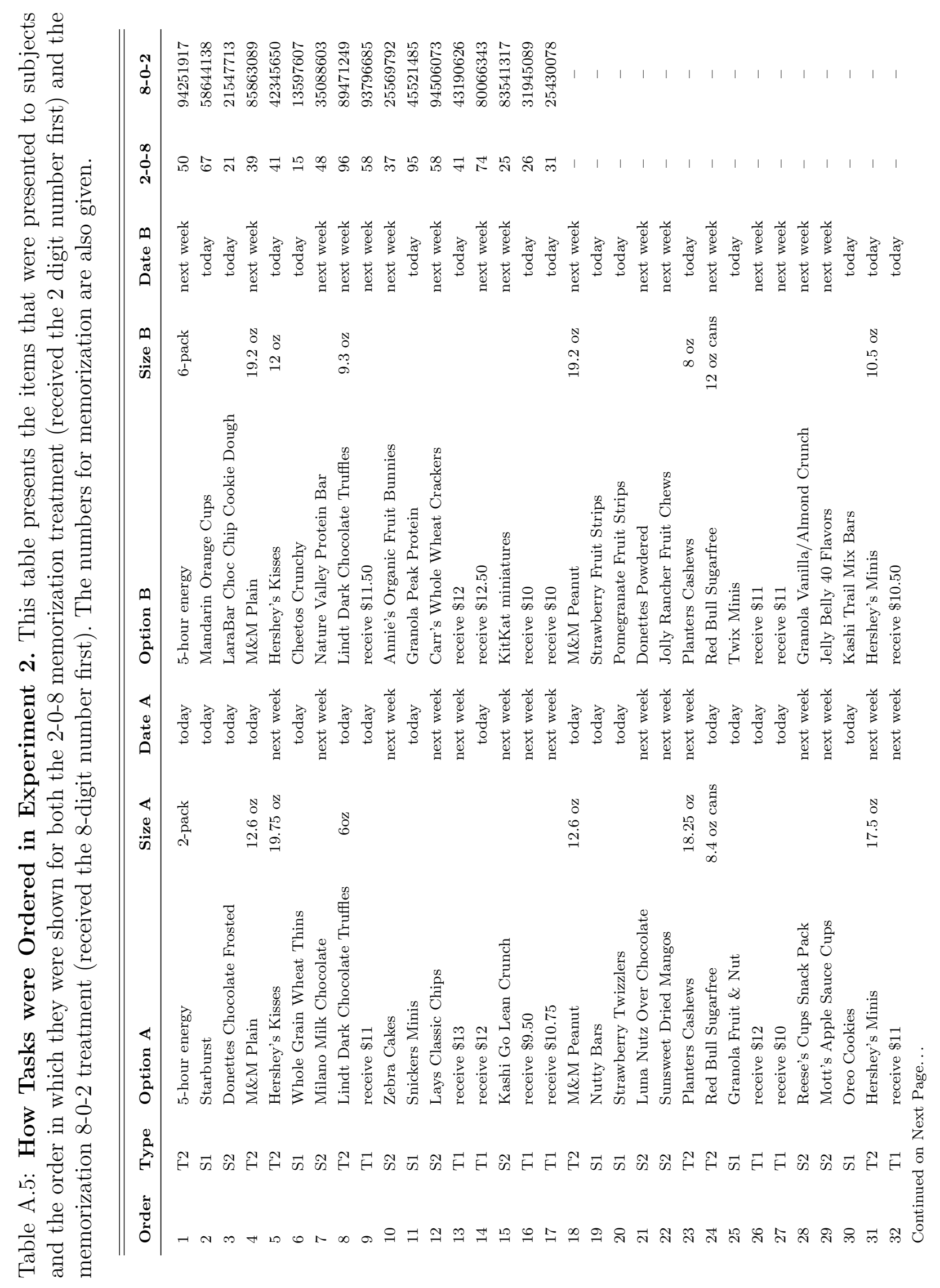




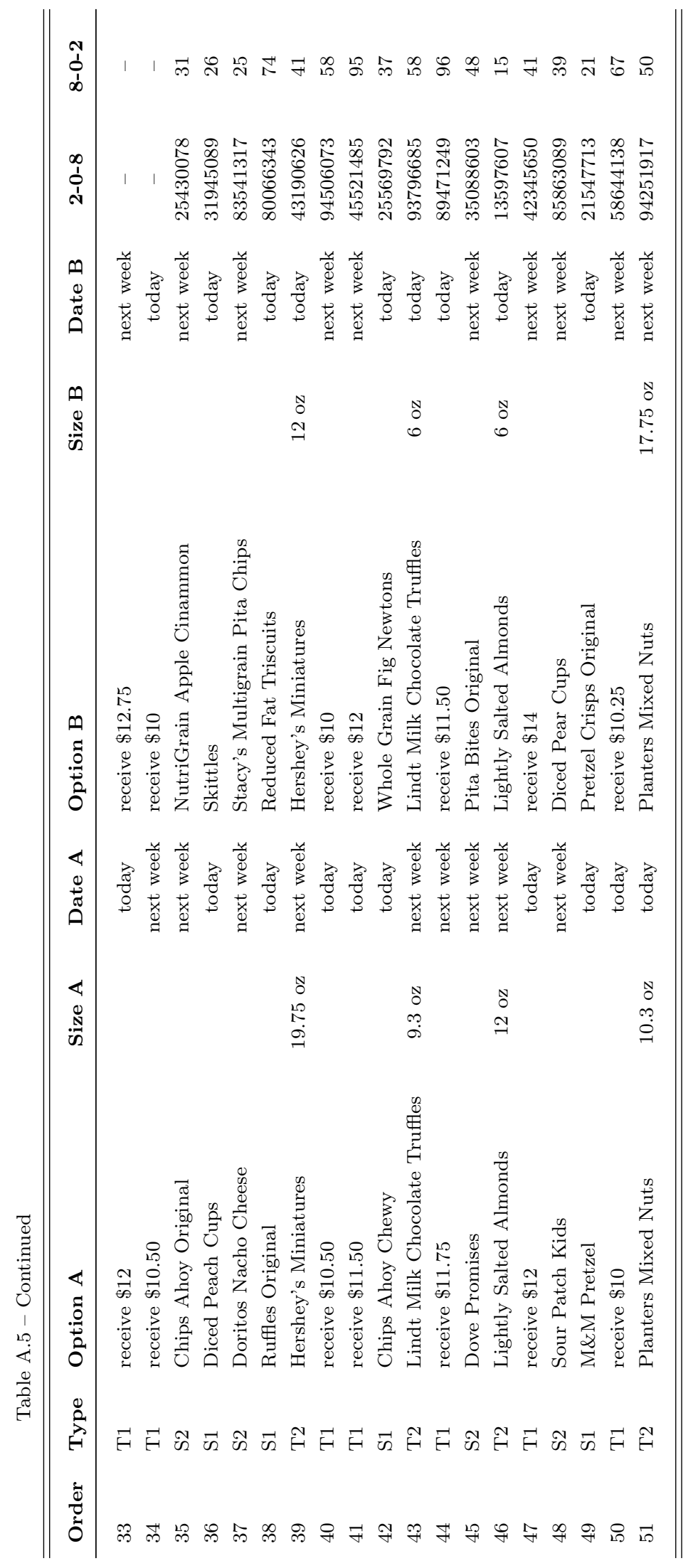




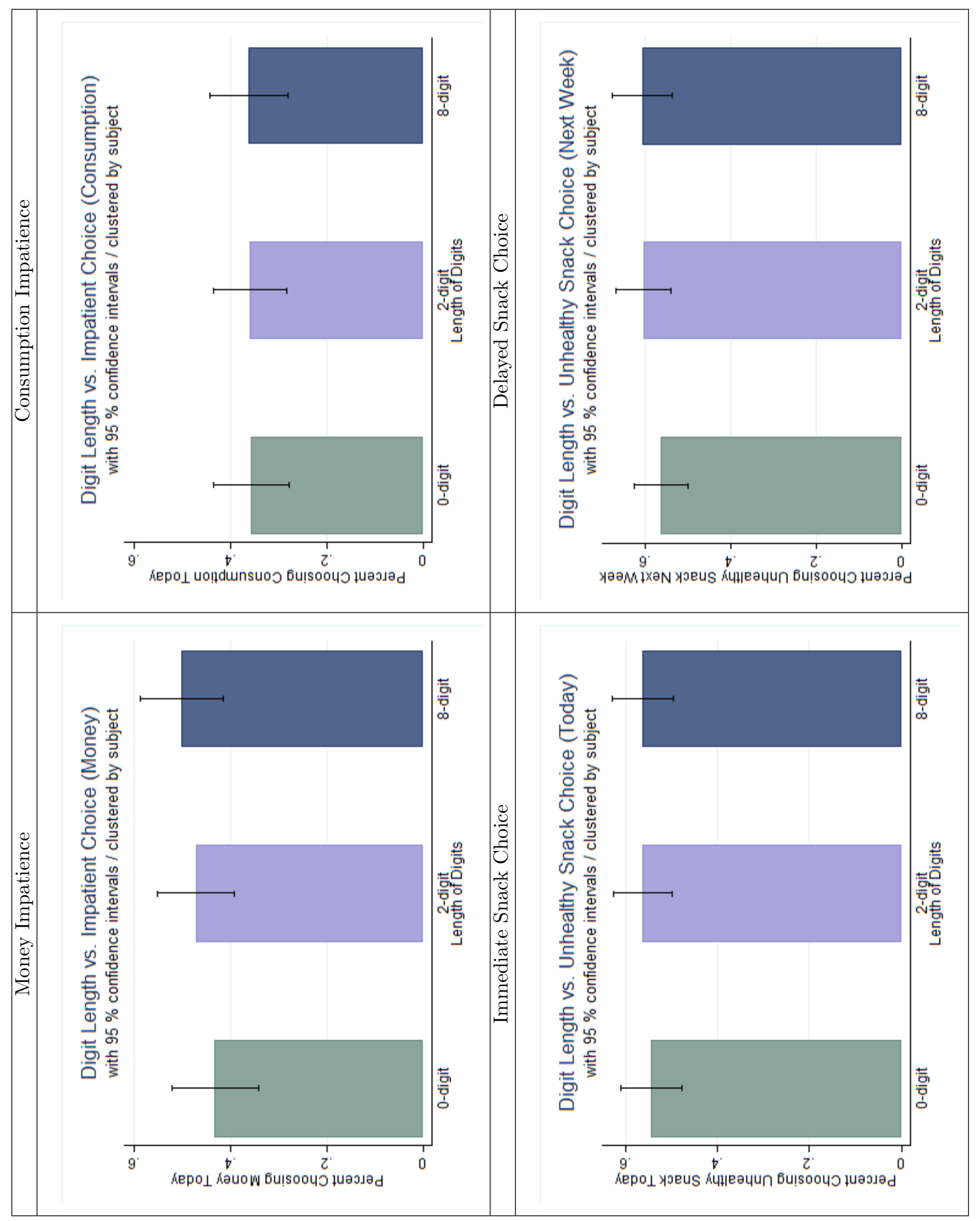

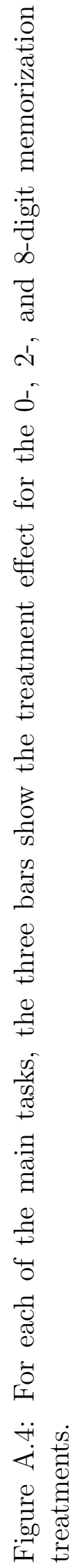




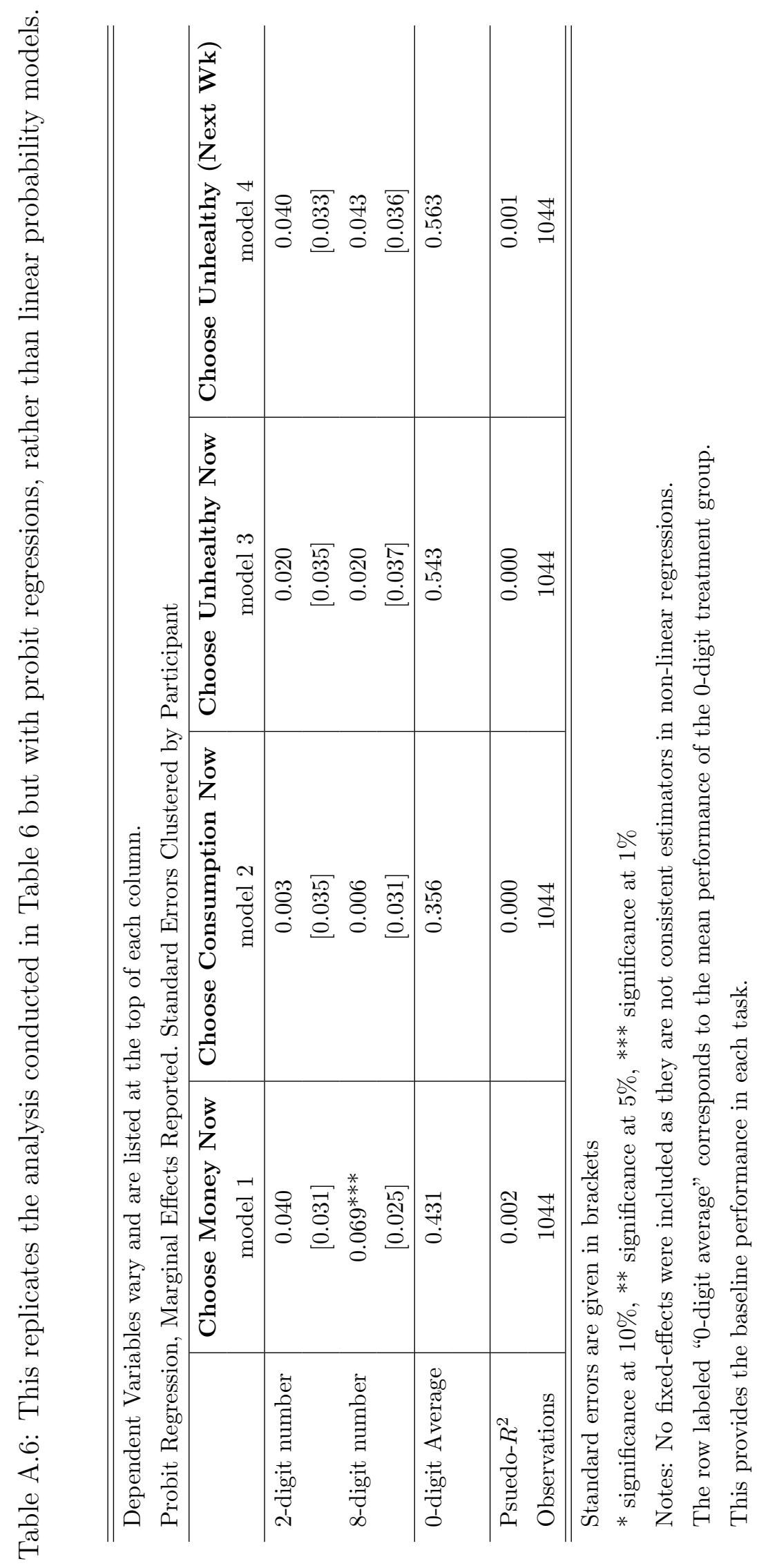




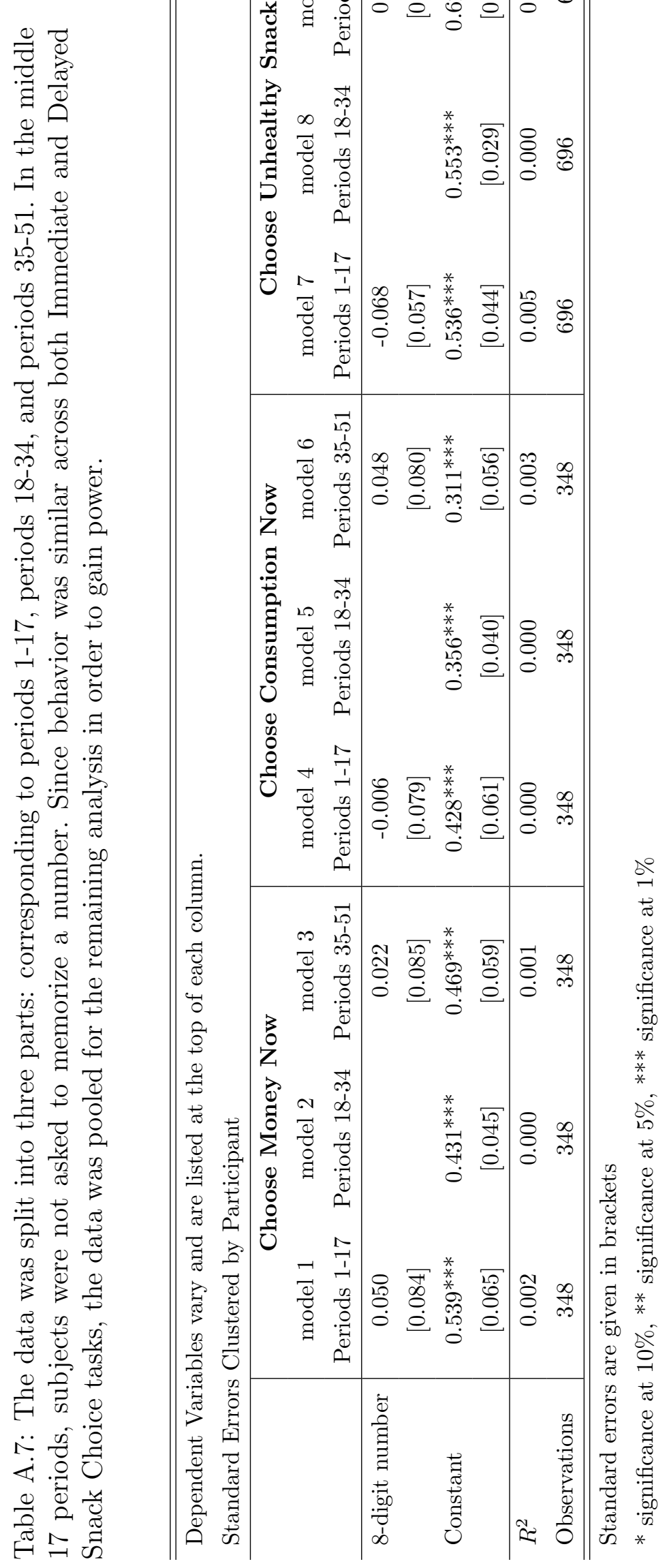

